BÁRBARA DARIANO SILVA

AVALIAÇÃO DE USABILIDADE SITUADA PARA APERFEIÇOAMENTO DE EQUIPAMENTOS MÉDICOS

São Paulo

2008 


\title{
AVALIAÇÃO DE USABILIDADE SITUADA PARA APERFEIÇOAMENTO DE EQUIPAMENTOS MÉDICOS
}

\author{
Dissertação apresentada à Escola \\ Politécnica da Universidade de São Paulo \\ para a obtenção do Título de Mestre em \\ Engenharia Elétrica \\ Área de Concentração: Sistemas Digitais \\ Orientadora: Prof ${ }^{a}$. Dr ${ }^{a}$. Lucia Vilela Leite \\ Filgueiras
}

São Paulo

2008 


\section{FICHA CATALOGRÁFICA}

\section{Silva, Bárbara Dariano}

Avaliação de usabilidade situada para aperfeiçoamento de equipamentos médicos I B.D. Silva. -- São Paulo, 2008.

89p.

Dissertação (Mestrado) - Escola Politécnica da Universidade de São Paulo. Departamento de Engenharia de Computação e Sistemas Digitais.

1. Usabilidade de software 2. Equipamentos e provisões hospitalares 3. Interface homem-computador I. Universidade de São Paulo. Escola Politécnica. Departamento de Engenharia de Computação e Sistemas Digitais II. t. 
Dedico este trabalho aos meus primeiros mestres, meus pais, Rita e João Inácio e ao meu irmão Victor 


\section{AGRADECIMENTOS}

À Prof a. Dr a. Lucia Vilela Leite Filgueiras, minha orientadora, pelos ensinamentos, paciência e orientações, contribuindo para meu crescimento científico e intelectual.

À Dixtal Biomédica, pelo apoio e disposição de recursos.

A meus colegas de trabalho da Dixtal Biomédica, pelo companheirismo, pelas idéias e pelo encorajamento, em especial, Ana Paula Brambila, Flávio Nishikawa Vilani, Marcelo Blechner e Elder Vieira Costa que acompanharam este trabalho desde o início.

Ao Prof. Dr. Francisco Garcia Soriano, pela colaboração no trabalho realizado no Hospital Universitário da USP.

À sra. Wilma Monteiro Frésca do Comitê de Ética em Pesquisa do Hospital Universitário da USP, pela atenção.

Aos funcionários da UTI do Hospital Universitário, de quem sem a colaboração e vontade de contribuir este trabalho não teria sido realizado.

A meus queridos pais, Rita e João Inácio, meu irmão Victor e toda minha família, por todo apoio e pelas palavras preciosas de motivação que foram determinantes para a realização desta pesquisa.

Ao querido Marcelo Takashi Suzuki pelo carinho e pelo encorajamento.

Aos amigos que fiz durante o mestrado e por causa dele.

A todos os meus amigos pela alegria e amizade que fazem os fardos da vida serem mais leves.

Enfim, a todos que contribuíram direta ou indiretamente para a realização deste trabalho. 


\section{RESUMO}

Este trabalho propõe uma estratégia para realizar uma avaliação de usabilidade situada de equipamentos médicos. A área da saúde tem feito cada vez mais uso da tecnologia da informação e a cada dia, o usuário de sistemas médicos se depara com mais equipamentos dotados de interfaces computacionais mais complexas. Avaliações de usabilidade tornam-se necessárias para garantir que o equipamento atenda as demandas das atividades dos profissionais da saúde e para minimizar a probabilidade de erros relacionados à interação com o sistema. Propõese, neste trabalho, uma estratégia para realizar a avaliação de usabilidade no ambiente de uso do equipamento. A estratégia proposta é avaliada em um estudo de caso com a avaliação de um monitor multiparamétrico dentro de uma UTI (Unidade de Terapia Intensiva), concluindo-se que ela se mostra útil ao processo de desenvolvimento, pois produz resultados de natureza diferente dos geralmente encontrados em laboratório. Adicionalmente, discutem-se os aspectos de ética envolvidos na avaliação situada de usabilidade.

Palavras-chaves: avaliação de usabilidade; interface humano-computador de sistemas médicos; avaliação situada 


\begin{abstract}
This paper considers a strategy to perform a situated usability evaluation of medical equipments. The use of information technology in the health sector has increased, as a result, medical system users need to deal with a complex computer interface that becomes even more complex each day. Usability evaluation become useful to ensure that the equipment fullfills healthcare professionals' demands and also minimize the probability of errors associated with computer-human interaction. In this study a strategy to do a usability evaluation on the equipments' intended environment has been proposed. The proposed strategy is evaluated in a case study with a multiparameter monitor in an ICU (Intensive Care Unit), concluding that it is useful to the development process because it produces different kinds of results when compared to those found in laboratories. This study also discusses the issues of ethics involved in the usability situated evaluation .
\end{abstract}

Keywords: usability evaluation; computer-human interfaces of medical system; situated evaluation 


\section{LISTA DE SIGLAS E ABREVEATURAS}

ABERGO Associação Brasileira de Ergonomia

ACM

Association for Computing and Machinery

AET

Análise Ergonômica do Trabalho

ASU

Avaliação Situada de Usabilidade

CEP

Comitê de Ética em Pesquisa

CONEP

Comissão Nacional de Ética em Pesquisa

CREA

Conselho Regional de Engenharia e Arquitetura

ECG

Eletrocardiograma

$\mathrm{HU}$

Hospital Universitário

IEC

International Eletrotechnical Commission

ISSO

International Organization for Standardization

SISNEP

Sistema Nacional de Informações sobre Ética em Pesquisa

UPA

Usability Professionals' Association

USP

Universidade de São Paulo

UTI

Unidade de Terapia Intensiva 


\section{SUMÁRIO}

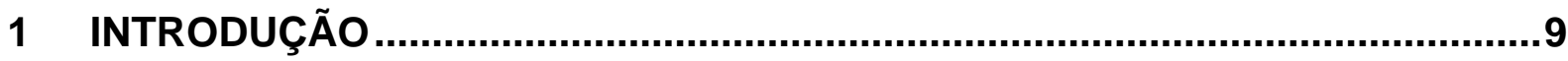

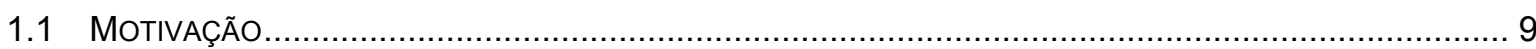

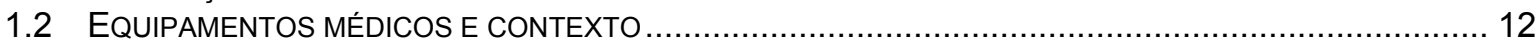

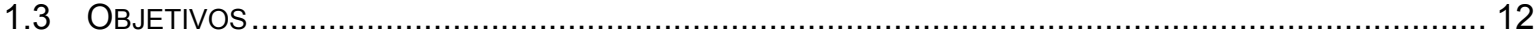

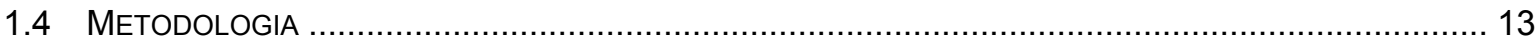

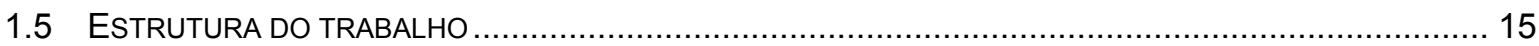

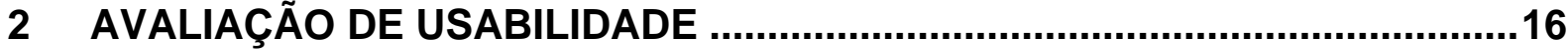

2.1 USABILIDADE

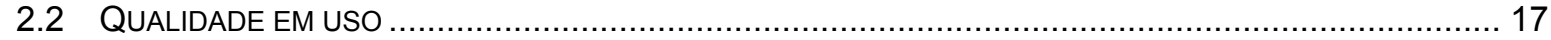

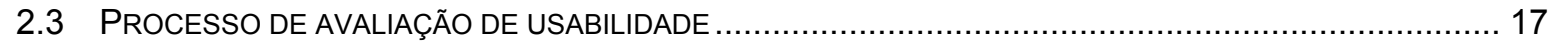

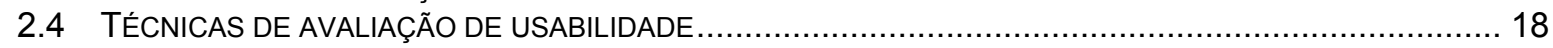

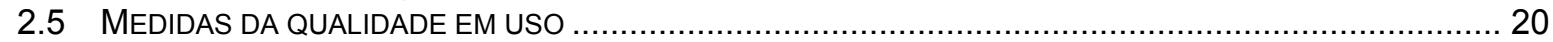

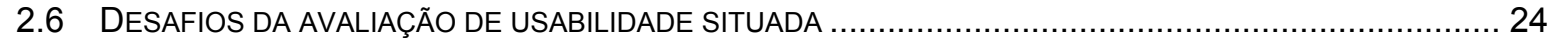

2.7 CONSIDERAÇÕES SOBRE AS TÉCNICAS DE AVALIAÇÃO DE USABILIDADEE ......................................... 25

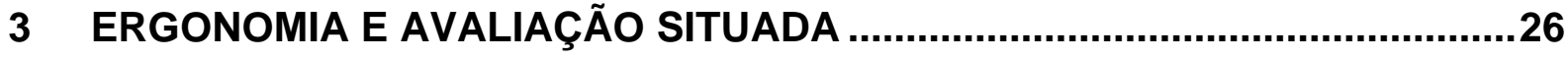

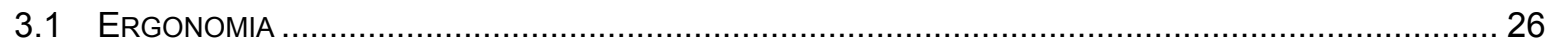

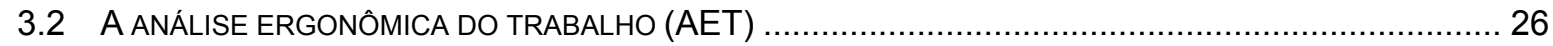

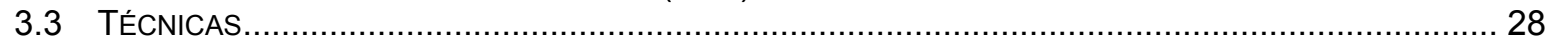

3.4 CONSIDERAÇÕES GERAIS SOBRE OS MÉTODOS DA ERGONOMIA .................................................. 29

4 ESTRATÉGIA PARA A AVALIAÇÃO SITUADA DE USABILIDADE EM EQUIPAMENTOS MÉDICOS..........................................................................31

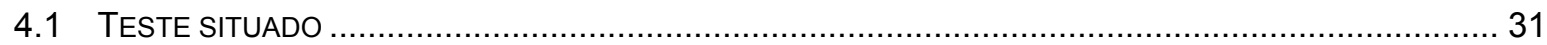

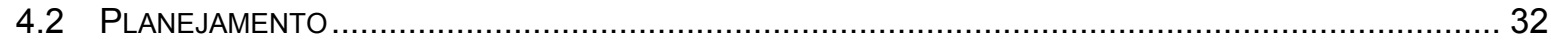

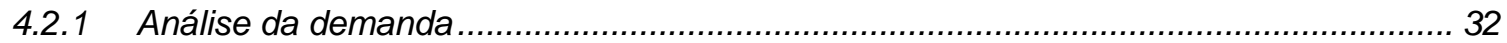

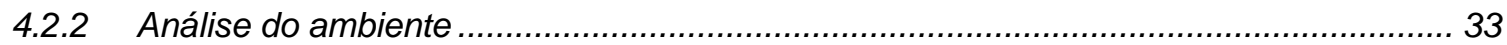

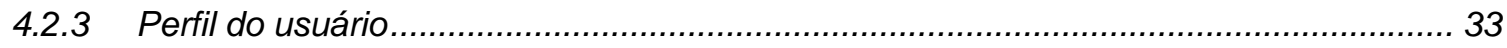

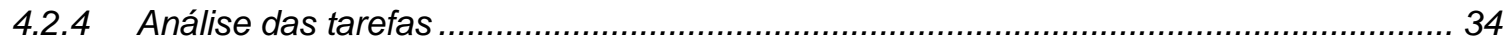

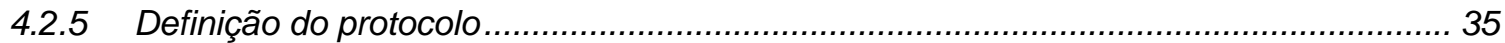

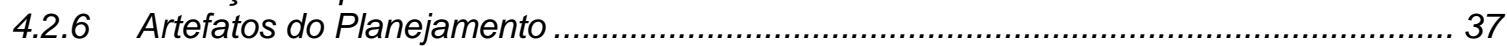

4.2.7 Submissão do protocolo ao comitê de ética.............................................................. 38

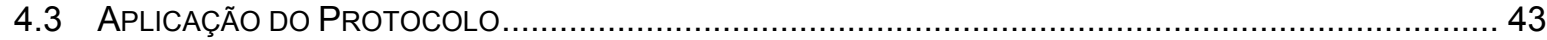

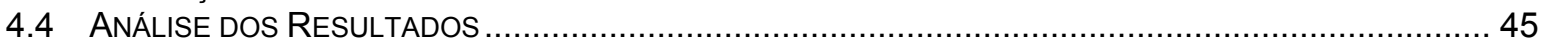

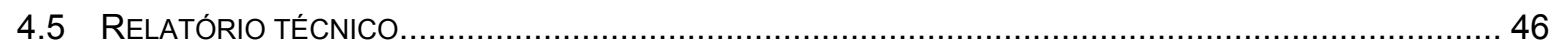

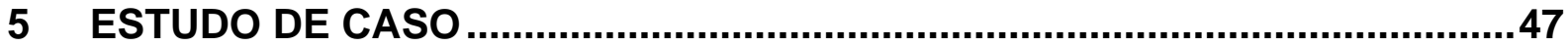

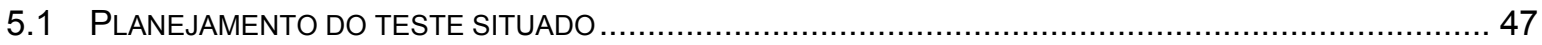

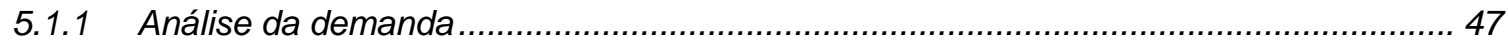

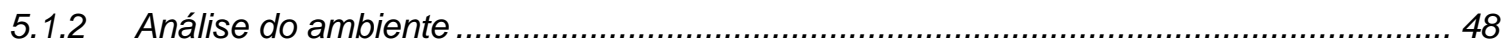

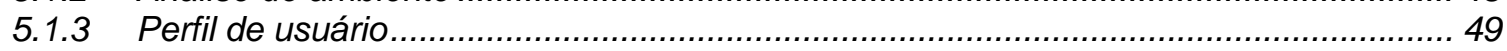

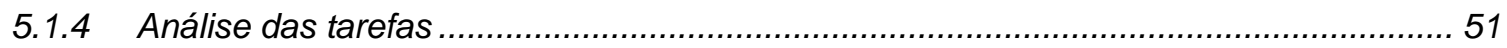

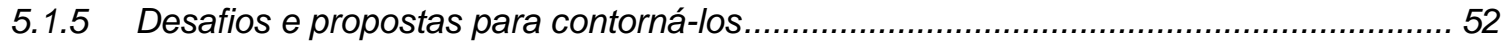

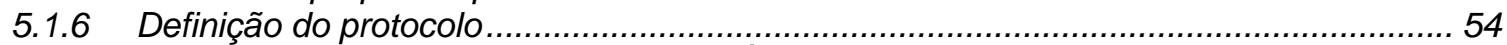

5.1.7 Submissão do protocolo ao Comitê de Ética em Pesquisa........................................... 55

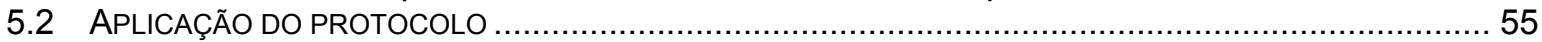

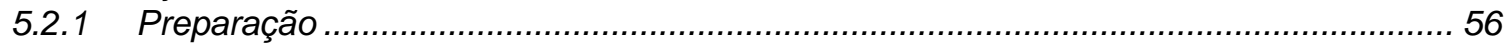

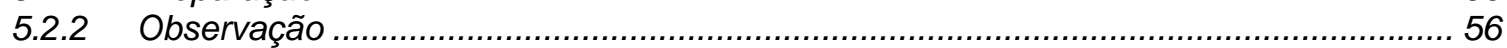

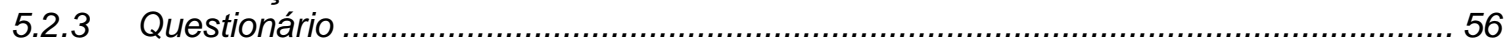

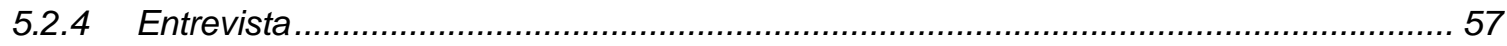

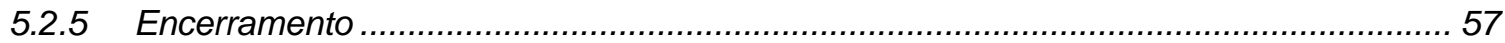

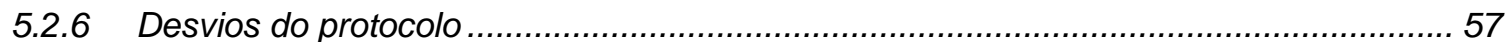

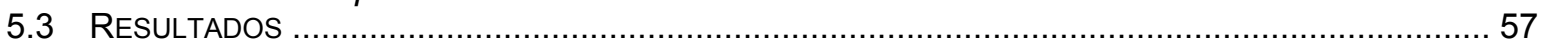

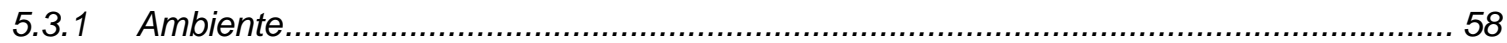

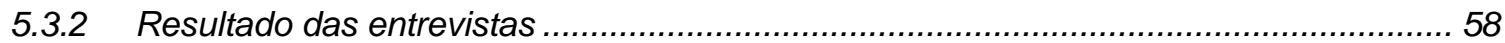

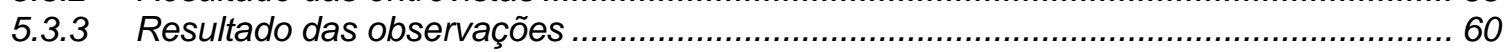




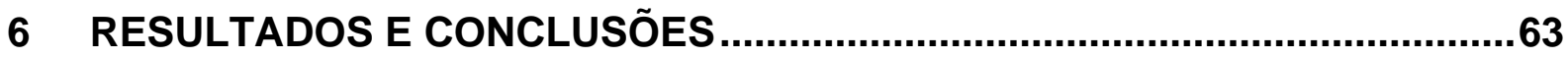

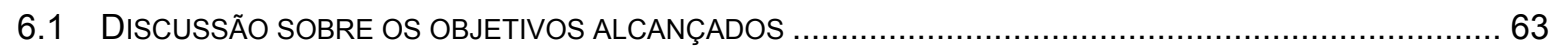

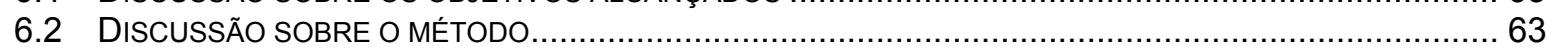

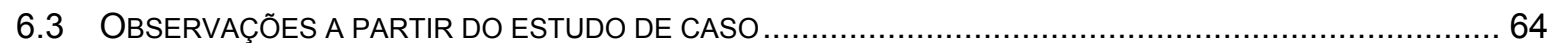

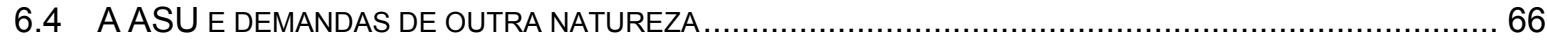

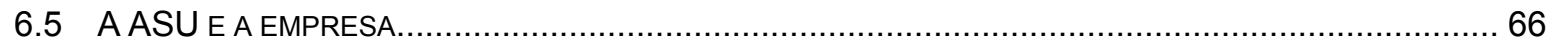

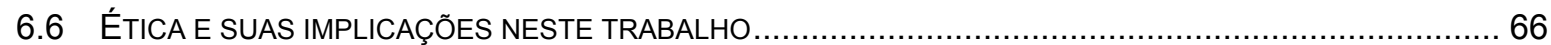

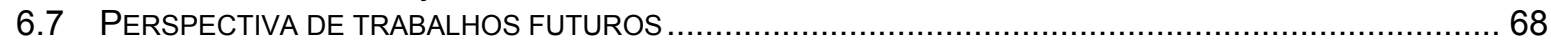

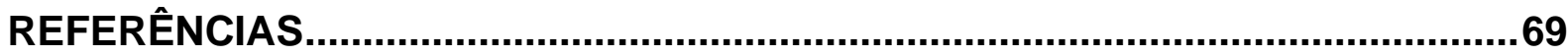

APÊNDICE I - INSTRUMENTO DE OBSERVAÇÃO ............................................75 APÊNDICE II - INSTRUMENTO DE LEVANTAMENTO DE PERFIL DE USUÁRIO 76

APÊNDICE III - INSTRUMENTO DE ENTREVISTA .77

APÊNDICE IV - INSTRUMENTO DE OBSERVAÇÃO DE SIMULAÇÃO DA

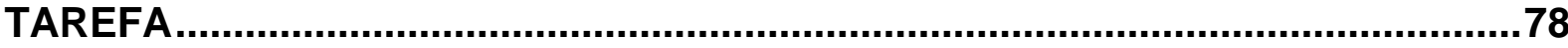

APÊNDICE V - DOCUMENTOS ENTREGUES AO CEP - HUIUSP .......................79 


\section{Introdução}

Nesta pesquisa foi realizado o estudo das técnicas de avaliação de usabilidade e elaborado uma proposta de aplicá-las no ambiente de uso de equipamentos médicos para levantar requisitos para o aprimoramento desses equipamentos.

Neste capítulo serão apresentados os objetivos do trabalho, a motivação e a organização deste texto.

\subsection{Motivação}

Para reduzir custos e processos ineficientes e aumentar a qualidade do cuidado com os pacientes, a área da saúde tem feito cada vez mais uso da tecnologia da informação e a cada dia, o usuário de sistemas médicos se depara com mais equipamentos médicos dotados de interfaces computacionais mais complexas.

Segundo a definição fornecida pela IEC (International Eletrotechnical Commission) na norma 60601-1 (2005), um equipamento médico é

“...qualquer instrumento, aparelho, implementação, máquina, aplicação, implantação, reagente in vitro ou calibrador, software, material ou outro similar ou artigo relacionado, que tenha como uso pretendido pelo fabricante, isoladamente ou em combinação, para seres humanos um ou mais objetivos específicos de :

- diagnóstico, prevenção, monitoração, tratamento ou alívio de doenças;

- diagnósticos, monitoração, tratamento, alívio ou compensação de um dano;

- investigação, reposição, modificação ou suporte da anatomia ou processo fisiológico;

- $\quad$ suporte e sustentação da vida;

- $\quad$ controle de concepção;

- desinfecção de equipamentos médicos;

- provisão de informações para propósitos medicinais por meio de exame de espécimes derivados do corpo humano."

Equipamentos médicos da geração mais antiga têm, em geral, como interface de apresentação, informações textuais e como interface de atuação, botões, seletores e linhas de comando. Na nova geração, as interfaces estão cada vez mais requintadas, trazendo gráficos, imagens, telas de navegação, comandos por toques 
em tela (touch screen), comandos por voz, mensagens de alerta, informações de apoio à decisão e diversas outras coisas que a tecnologia pode proporcionar.

Os equipamentos e sistemas médicos com interfaces computacionais estão presentes em todos os ambientes de atuação dos profissionais da saúde. Nas Unidades de Terapia Intensiva (UTIs) podem ser encontrados monitores de sinais vitais, equipamentos de suporte à vida. Em consultórios, são comumente vistos medidores de pressão e de oxigenação sangüínea; nos laboratórios, as tomografias computadorizadas e equipamentos de diagnósticos; nas salas de cirurgia, equipamentos sofisticados de procedimentos cirúrgicos, softwares de administração de drogas, e muitos outros.

A tecnologia aplicada à medicina tem se tornado cada vez mais importante no moderno cuidado com os pacientes. Esse aumento do uso de tecnologia aumenta as possibilidades de diagnóstico e tratamento, mas, também aumentam a complexidade do cuidado com a saúde (LILJEGREN, 2006).

Quanto mais se faz uso da computação e da tecnologia da informação, é possível que os erros associados à interação humano-computador cresçam proporcionalmente (REASON, 1990).

Uma série de estudos mostra que uma porcentagem considerável dos problemas ocorridos dentro das unidades de atendimento médico é provocada por falha humana. De acordo com Leape (1994) cerca de 69\% dos prejuízos à saúde dos pacientes são provocados por falhas ou erros humanos. Entre 69 e $82 \%$ de problemas durante a anestesia são ocasionados por falha humana. Um projeto deficiente pode provocar tais falhas (HYMAN, 1994).

As tarefas dos profissionais da saúde têm uma carga cognitiva associada elevada e na maioria das vezes exigem um tempo de resposta muito pequeno. Algumas tarefas exigem respostas imediatas. Considerando isso, os equipamentos introduzidos nesse ambiente de trabalho não devem aumentar a carga cognitiva e nem exigir tempo ou dedicação do usuário.

Para que os equipamentos médicos possam desempenhar sua função adequadamente, além de sua funcionalidade e aspectos de segurança, como contaminações e interferências eletromagnéticas, um outro aspecto precisa ser considerado ao projetar, produzir, comprar e utilizar esses aparelhos: a interação dos usuários com eles. 
A interação do usuário com o equipamento e a carga cognitiva associada ao uso do aparelho podem ser avaliadas com as técnicas de avaliação da usabilidade.

Mas, atualmente, essa avaliação tem sido feita, na maior parte das vezes, em laboratório, utilizando pessoal que, em sua maioria, difere bastante do perfil do usuário comum. Isso se dá, principalmente por questões de confidencialidade, associadas ao negócio. Essa afirmação pode ser encontrada na literatura (LIU et al. 2004) e também pôde ser comprovada pela experiência profissional da autora deste trabalho.

Esse tipo de avaliação levanta aspectos relevantes da usabilidade, porém, uma desvantagem que pode ser vista na avaliação em laboratório é que o peso da carga cognitiva associada à atividade principal, que no caso em questão é cuidar dos pacientes, não é considerada adequadamente.

Sabe-se que as avaliações realizadas no ambiente de uso do equipamento, com situações e usuários mais próximos das condições reais de utilização, produzem um resultado diferente da avaliação em laboratório, pois é possível identificar com mais clareza as dificuldades e necessidades dos usuários, possibilitando alterações de projeto mais efetivas (KJELDSKOV e STAGE , 2004). Essa tem sido uma questão aberta, que se manifesta em diversas áreas e incentivou recentemente uma discussão acadêmica em um importante evento na área de IHC o workshop: Technology has Escaped from the Zoo: Studying Usability in the Wild, no INTERACT 2007).

Com um estudo em campo podem-se obter informações a respeito do conforto ou desconforto do usuário no uso do equipamento e levantar suas necessidades mais relevantes para realizar suas tarefas de forma mais rápida e adequada, aumentando consequentemente a eficiência dos tratamentos e as probabilidades de sobrevivência dos pacientes em casos de emergência.

O aspecto mais relevante ao realizar uma avaliação de usabilidade situada é propor alterações e inovações nos equipamentos, seja de disposição nos ambientes de trabalho dos profissionais da saúde seja na forma de apresentação das informações ou ainda na criação de novas funcionalidades, que minimizem os erros e falhas humanas possibilitando um ambiente mais agradável para os profissionais da saúde e aumentando as probabilidades de sobrevivência dos pacientes.

Por se tratar de um trabalho acadêmico na área de computação, nesta pesquisa será dada ênfase ao equipamento e não ao ambiente de trabalho. 


\subsection{Equipamentos médicos e contexto}

Os equipamentos médicos estão inseridos em um contexto formado pelo ambiente, pelos usuários, pelo paciente e sua doença e pelo conjunto de equipamentos usados.

O ambiente físico, ou seja, as suas dimensões, a iluminação, os ruídos e o mobiliário, varia conforme a unidade de atendimento (pronto atendimento, centro cirúrgico ou unidade de terapia intensiva) e varia também de hospital para hospital (número e disposição de leitos, outros equipamentos no ambiente). Essas diferenças alteram a disposição dos equipamentos, tanto por causa do espaço disponível como por causa das necessidades diferentes.

As relações sociais também variam conforme o hospital. Nos hospitais universitários existem um número maior de pessoas dentro do ambiente, por conta dos alunos e existe uma relação professor-aluno que em outros hospitais é quase inexistente.

Com relação aos usuários, dentro de uma mesma unidade de atendimento, existem vários grupos: os auxiliares de enfermagem, os técnicos de enfermagem, os enfermeiros, os médicos e os fisioterapeutas. Esses grupos realizam tarefas diferentes e portanto têm necessidades diferentes.

Os cuidados que cada paciente exige também são diferentes conforme as unidades de atendimento, embora não variem muito entre hospitais. Essa variação é motivada pela doença e pelo quadro clínico do paciente. Algumas enfermidades exigem que o paciente seja acomodado em uma área de isolamento, ou porque ele corre risco de ser infectado, ou porque ele pode infectar visitantes e outros pacientes. Esse é um dos fatores que faz o ambiente hospitalar ser um ambiente crítico.

\subsection{Objetivos}

O objetivo deste trabalho é propor uma estratégia para realizar avaliações situadas de usabilidade em equipamentos médicos.

Para isso são pesquisadas as técnicas de avaliação de usabilidade existentes para determinar quais poderão ser aplicadas em um ambiente hospitalar.

Nesse estudo de viabilidade da utilização das técnicas, é preciso considerar que o ambiente hospitalar é um ambiente crítico. Para trabalhar nele, o especialista 
em usabilidade necessita se adequar às rotinas desenvolvidas nele, preparando sua intervenção para obter os resultados desejados sem quebrar regras éticas e protegendo a privacidade dos trabalhadores, pacientes e seus familiares.

Assim, a estratégia proposta inclui recomendações de atuação do profissional de usabilidade no ambiente hospitalar.

Para redução do escopo nesse trabalho serão considerados apenas os equipamentos de monitoração (monitores multiparamétricos). O monitor multiparamétrico é um equipamento médico de monitoração dos sinais vitais (pressão arterial invasiva ou não invasiva, freqüência cardíaca, freqüência respiratória, saturação de oxigênio entre outros) em que mais de um parâmetro pode ser visualizado simultaneamente (LILJEGREN et al. 2004).

Nesses equipamentos algumas configurações podem ser realizadas como o volume, severidade e limites de alarmes e filtragens dos sinais para melhor visualização do parâmetro na tela do equipamento. Além disso, alguns desses monitores fornecem recursos de cálculo e avaliação de tendência do quadro do paciente.

Esse tipo de equipamento foi escolhido para estudo, porque é possível limitar o número de funcionalidades observáveis; e a motivação de estudá-lo inserido em uma UTI é o fato desse ambiente ser mais controlado do que um centro cirúrgico, por exemplo. Além disso, na UTI, uma vez que o enfoque é o uso, existem diversas oportunidades de observação em um mesmo espaço (as UTIs costumam ter cerca de 10 monitores multiparamétricos).

Uma outra razão desta escolha é o acesso da autora a esse tipo de equipamento nesse tipo de ambiente. A autora atua na área de desenvolvimento da DIXTAL Biomédica, empresa que desenvolve e produz equipamentos médicos, em especial monitores multiparamétricos.

\subsection{Metodologia}

Este trabalho parte das seguintes premissas:

- As avaliações de usabilidade são necessárias para melhorar a qualidade de sistemas interativos. As técnicas de avaliação de usabilidade são conhecidas e têm eficácia comprovada. 
- Os equipamentos médicos são sistemas críticos do ponto de vista da ação humana e por isso, precisam passar por avaliações criteriosas de usabilidade.

- As técnicas de avaliação de usabilidade, realizadas em laboratório, embora eficazes e necessárias, não capturam adequadamente a influência do contexto de uso real.

- O ambiente hospitalar, no qual são usados os equipamentos médicos, possui um contexto específico de trabalho que afeta significativamente o uso.

Sobre estas premissas, deseja-se verificar o seguinte fato: para obter a melhoria da qualidade de uso dos equipamentos médicos, é necessária uma estratégia de avaliação situada de usabilidade que, ao mesmo tempo, permita reconhecer a qualidade de uso do equipamento médico, sujeita às variações do ambiente hospitalar, e seja uma intervenção adequada do ponto de vista da ética e regras de trabalho deste ambiente.

Do ponto de vista da natureza, este trabalho pretende ser uma pesquisa aplicada, ou seja, tem o objetivo de propor uma forma de aplicar o conhecimento para a solução de um problema específico - neste caso, avaliar a interação do usuário com equipamentos médicos fornecendo informações para melhorias no equipamento e para o projeto de novos equipamentos.

A abordagem do problema será a de uma pesquisa qualitativa uma vez que o foco principal é o processo de pesquisa.

Com relação aos procedimentos técnicos, foram adotados os seguintes:

- Pesquisa bibliográfica: revisão da literatura para levantar as técnicas disponíveis para realizar a avaliação de usabilidade. A pesquisa bibliográfica tem como foco os processos de avaliação de usabilidade na literatura de Interação Humano-Computador $(\mathrm{IHC})$ e os processos de análise ergonômica da literatura de Ergonomia.

- Pesquisa participante: a pesquisadora tem contato direto com desenvolvedores de equipamentos e seus usuários em ambiente hospitalar, possibilitando um resultado mais adequado à realidade destes dois grupos. 
- Pesquisa experimental: as técnicas de avaliação e as formas de controle definidas são aplicadas no ambiente hospitalar, observando-se os resultados.

\subsection{Estrutura do trabalho}

Este trabalho está estruturado da seguinte forma:

- Capítulo 1 - é esta Introdução

- Capítulo 2 - Avaliação de Usabilidade: são apresentados conceitos relevantes para este trabalho como a usabilidade, fatores de qualidade e contexto de uso.

- Capítulo 3 - Ergonomia e avaliação situada: onde serão apresentados conceitos de ergonomia que serão incorporados a avaliação de usabilidade.

- Capítulo 4 - Estratégia para avaliação situada de usabilidade em equipamentos médicos: considerando as técnicas apresentadas nos capítulos anteriores, faz-se uma proposta de aplicá-las em campo;

- Capítulo 5 - Estudo de Caso: descrição da aplicação do procedimento proposto no capítulo anterior;

- Capítulo 6 - Resultados e Considerações: análise dos resultados obtidos no experimento, discussão sobre questões éticas que surgiram ao longo do trabalho e conclusões.

- Referências: este item da dissertação inclui os materiais utilizados durante esta pesquisa;

- Apêndices: os instrumentos de pesquisa elaborados e utilizados no experimento e outros documentos de apoio; 


\section{Avaliação de Usabilidade}

Neste capítulo pretende-se conceituar usabilidade e avaliação de usabilidade. Pretende-se também comparar as técnicas para encontrar, entre elas, aquelas que possam ser utilizadas em ambiente hospitalar e que possam proporcionar resultados adequados aos objetivos deste trabalho.

\subsection{Usabilidade}

Os projetistas precisam estar atentos à necessidade de satisfazer os usuários de seus produtos, aumentando a usabilidade (LILJEGREN, 2006).

A usabilidade não é uma propriedade singular, é antes, um conjunto de diferentes propriedades e atributos. A ISO define a usabilidade em duas situações.

$\mathrm{Na}$ área de Engenharia de Software, usabilidade é uma das características de qualidade de software, definida pela ISO 9126-1 (2001) como:

"The capability of the software product to be understood, learned, used and attractive to the user, when used under specified conditions."

Como característica de qualidade externa e interna de software, usabilidade possui as seguintes subcaracterísticas:

"Understandability

The capability of the software product to enable the user to understand whether the software is suitable, and how it can be used for particular tasks and conditions of use. .

Learnability

The capability of the software product to enable the user to learn its application

Operability

The capability of the software product to enable the user to operate and control it.

Attractiveness

The capability of the software product to be attractive to the user.

Usability compliance

The capability of the software product to adhere to standards, conventions, style guides or regulations 
relating to usability."

$\mathrm{Na}$ área de Ergonomia, a ISO 9241-11 (1998) define usabilidade como sendo: "Extent to which a product can be used by specified users to achieve specified goals with effectiveness, efficiency and satisfaction in a specified context of use."

De acordo com Nielsen (1993), usabilidade só pode ser definida pelo conjunto de seus componentes: facilidade de aprendizado, eficiência, facilidade de memorização, poucos erros (isto é, o sistema não deve induzir o usuário ao erro e deve possibilitar a recuperação de um estado anterior ao acontecimento do erro) e satisfação subjetiva.

Observa-se, das várias definições, o caráter multifacetado da definição de usabilidade e a necessidade de que a característica seja definida por atributos que expressem de forma específica o conceito, de acordo com o sistema que se pretende analisar.

\subsection{Qualidade em uso}

A norma ISO 9126-1 (2001) apresenta, ainda, o conceito de qualidade em uso, que pode ser entendido como a qualidade que o usuário observa ao usar um determinado sistema em um dado ambiente. Esse conceito está relacionado com a experiência do usuário, que indiretamente faz parte da análise proposta.

A qualidade em uso é dividida nas seguintes características: eficácia, produtividade, segurança e satisfação.

A eficácia é a capacidade do usuário chegar ao objetivo, dado um determinado contexto. A produtividade é expressa pela relação entre a quantidade de recurso usada e a eficácia. A segurança está associada ao alcance de um estágio de risco aceitável em um determinado contexto. A satisfação é a capacidade de satisfazer o usuário em um determinado contexto.

\subsection{Processo de avaliação de usabilidade}

O objetivo de fazer uma avaliação de usabilidade é encontrar possíveis problemas que usuários podem enfrentar nas condições reais de uso. 
Seguindo as definições de usabilidade apresentadas anteriormente, antes de qualquer avaliação de usabilidade é preciso conhecer quem é o usuário do sistema, quais as tarefas que ele realiza e em que tipo de ambiente.

Para Liljegren (2004), a avaliação de usabilidade deve ser composta de três etapas:

- encontrar problemas

- determinar a severidade

- propor soluções

Os problemas são encontrados através da aplicação das técnicas de avaliação; a severidade pode ser determinada de acordo com a freqüência, o impacto e a persistência do problema; a proposta de solução pode ser feita por um especialista após a análise dos resultados obtidos.

Para obter um bom resultado é necessário um planejamento adequado da avaliação e a aplicação das técnicas adequadas. Nesse planejamento da avaliação e na escolha das técnicas, não se pode esquecer de avaliar as condições do ambiente e para que tipo de pessoas serão aplicadas.

Estudos em diversas áreas mostram que usuários com diferentes backgrounds (experiências anteriores e conhecimentos) encontram problemas diferentes (LIU et al. 2004). Por isso, para produzir resultados relevantes, a avaliação deve ser feita com uma população que represente os usuários reais.

\subsection{Técnicas de avaliação de usabilidade}

A usabilidade é tema de estudo há algum tempo em diversas áreas do conhecimento. Ao longo dos anos, uma série de técnicas de avaliação de usabilidade foram desenvolvidas e aplicadas de acordo com as características e as dificuldades dos objetos em estudo.

Para encontrar os problemas de usabilidade de equipamentos médicos não existe uma única técnica que possa fornecer todas as respostas, é preciso fazer uso de uma combinação de técnicas, considerando ainda as limitações do ambiente médico-hospitalar e de disposição dos usuários (LILJEGREN, 2006).

Estudos mostram que algumas técnicas possibilitam encontrar os problemas de usabilidade, em situações similares, com bastante êxito. 
Com base em diversos estudos sobre usabilidade em ambientes reais de uso (HAYNES, PURAO e SKATTEBO, 2004; BYRNE, GREENE e EVERETT, 2007; HALL, 2006;) e especificamente na área médica (LILJEGREN et al. 2004; LILJEGREN, 2006; LIU et al. 2004; HAN et al., 2007; KUSHNIRUK e PATEL, 2003; EDWARDS et al, 2006; SIEK e CONNELLY, 2006), neste trabalho serão considerados os seguintes técnicas de avaliação:

- análise da tarefa: permite descobrir quais são as atividades executadas no sistema e decidir quais funções serão analisadas;:

- entrevistas em contexto: esta é uma técnica que consiste observar o usuário em seu ambiente de realização de tarefas, sem determinar tarefas específicas para serem realizadas, tem um aspecto informal em que o observador analisa como as atividades estão sendo executadas. Esta técnica permite conhecer também o ambiente social do usuário, ajuda a descobrir se ele tem auxílio para executar suas tarefas ou se ele é interrompido com freqüência;

- grupo de foco: é uma discussão moderada baseada em tópicos previamente estabelecidos. Espera-se ao fim da discussão conhecer melhor as crenças, desejos e atitudes dos usuários e também suas reações a idéias e protótipos;

- entrevistas individuais: possibilitam entender as atitudes, desejos, crenças e experiências dos usuários através de seu próprio relato. Essa técnica pode ser aplicada por meio de questionários em papel, pela internet, por telefone ou pessoalmente. Esses questionários podem ser abertos, em que o entrevistado pode responder às perguntas como ele achar melhor, ou fechados, em que o entrevistado responde às perguntas de acordo com alternativas;

- questionários: essa técnica pode ser empregada a qualquer momento do ciclo de vida do sistema. Com esse método pode-se identificar os usuários do sistema, o que eles querem ao usar o sistema, que informação eles procuram, qual a experiência que eles tiveram com o sistema;

- cognitive walkthrough (percurso cognitivo): com base em uma seqüência definida e detalhada de tarefas são analisados os casos de 
sucesso ou não dos usuários ao realizá-las. Esta técnica é usada para levantar o modelo mental dos usuários.

\subsection{Medidas da qualidade em uso}

A norma da ISO 9126-4 (SOFTWARE ENGENEERING - PRODUCT QUALITY : PART 4 - QUALITY IN USE METRICS)(2004) apresenta métricas baseadas em normas de qualidade, engenharia de software e requisito de usabilidade para medir a qualidade de um produto de software de qualquer aplicação.

Essa métricas são colocadas através de um conjunto de questões que devem ser observadas durante a avaliação. Esse conjunto é amplo e genérico o bastante para possibilitar que sua adaptação seja feita para qualquer aplicação, inclusive aplicações médicas.

O foco deste trabalho é a qualidade em uso. É necessário, portanto, estabelecer o contexto de uso, ou seja, definir o perfil dos usuários, identificar as tarefas realizadas, os equipamentos envolvidos e ter uma visão do ambiente físico e social; e também estabelecer as métricas de qualidade em uso adequadas para a avaliação.

Pode-se extrair dessa norma um modelo de qualidade para diferenciar qualidade interna, qualidade externa e a qualidade em uso, como pode ser visto na figura 2.1. 


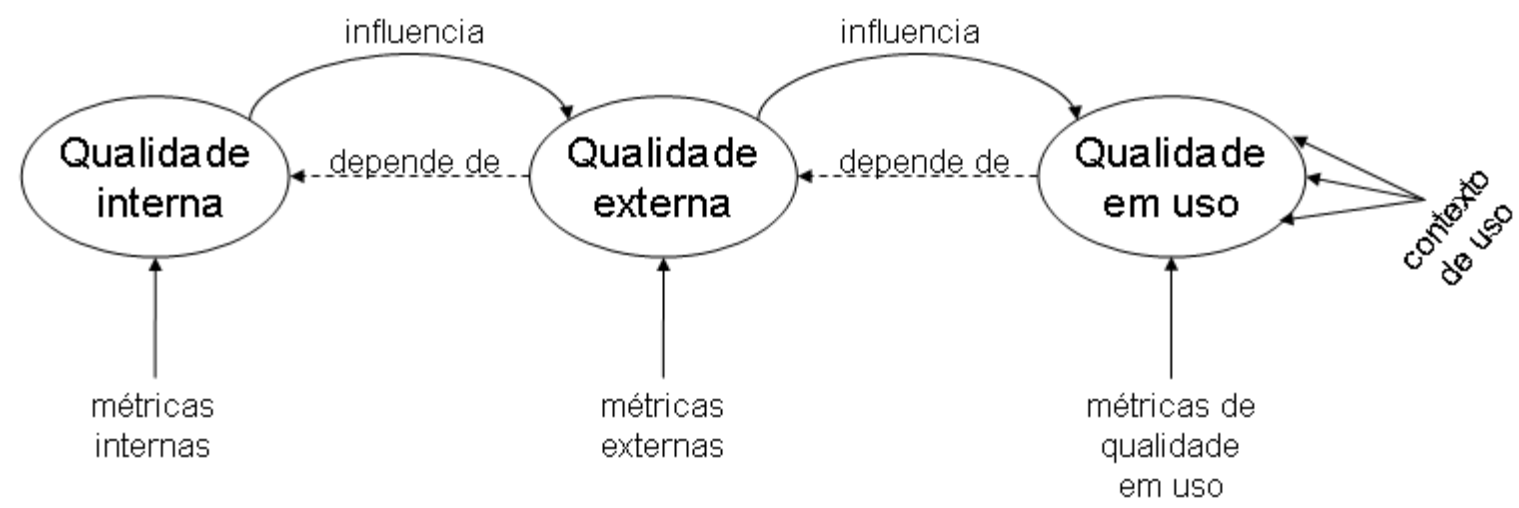

Figura 2. 1- Relação entre os tipos de métricas - traduzido de ISO 9126-4 página 3

As métricas internas podem ser aplicadas aos produtos de software nãoexecutáveis como por exemplo a definição de requisitos. Já as métricas externas são usadas para avaliar o comportamento do sistema. É recomendado que essas métricas sejam empregadas durante a fase de testes e/ou durante a fase operacional.

Pode-se sobrepor esse modelo de métricas de qualidade ao modelo de ciclo de vida de um sistema como se vê na figura 2.2.

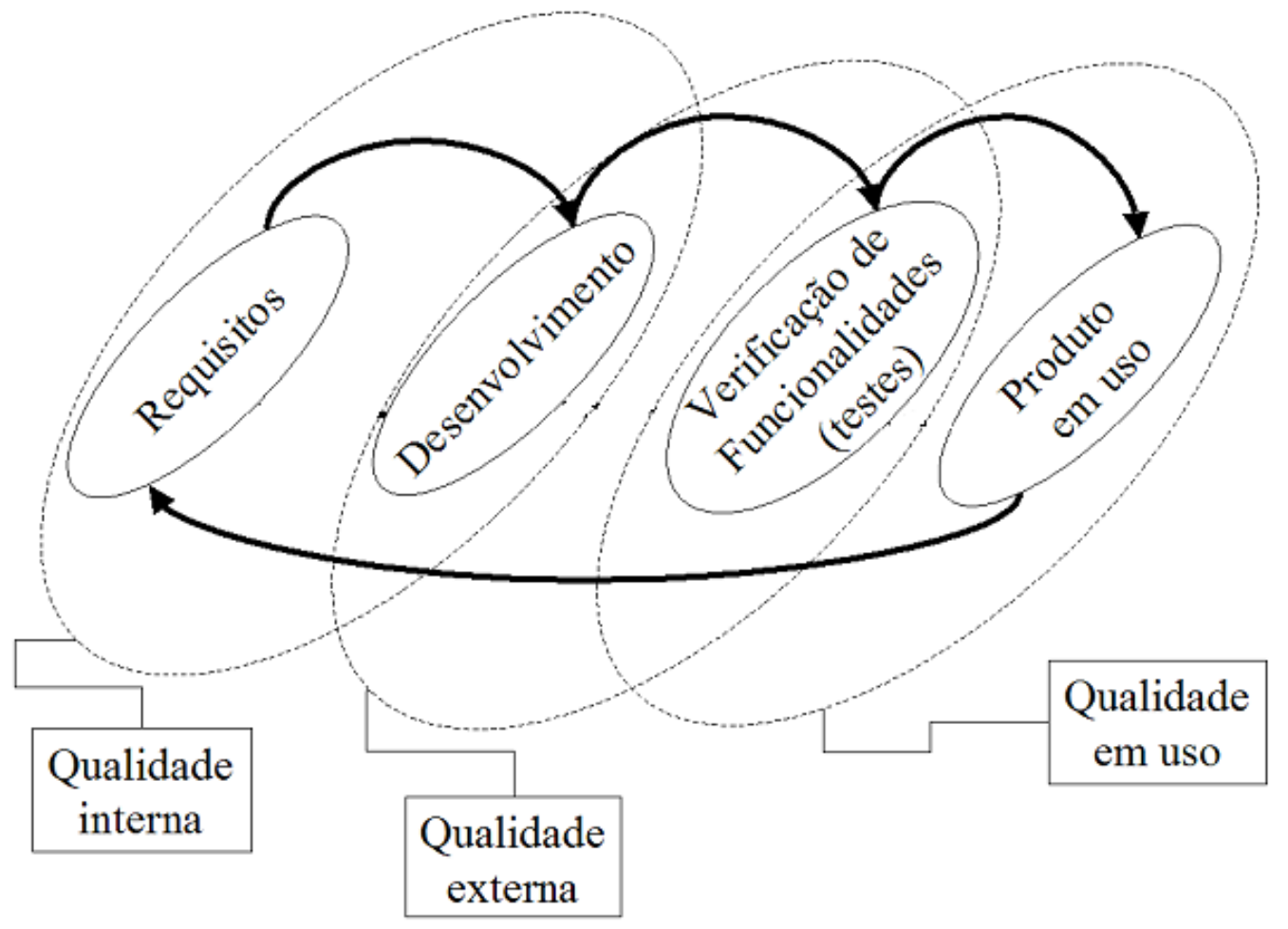


Figura 2. 2 - Ciclo de vida de software baseado na norma ISO 12207 associado com as métricas de qualidade

As métricas de qualidade de uso são utilizadas para verificar o atendimento das necessidades dos usuários para atingir objetivos específicos como eficiência, produtividade, segurança e satisfação em um contexto de uso específico.

O texto da norma apresenta uma tabela construída da seguinte maneira:

- objetivo da métrica: neste tópico é apresentada a questão que deve ser respondida ao se aplicar a métrica;

- método de aplicação;

- medidas, fórmulas e dados: fornece as fórmulas e explica o significado de cada dado utilizado para os cálculos;

- interpretação de valores: indica qual faixa de valores será usada e quais valores serão considerados adequados;

- tipo de escala métrica;

- tipo de medida;

- medidas de entrada: fonte de dados usados nas medidas;

- fase(s) em que a(s) métrica(s) pode(m) ser aplicada(s)

- "público alvo": indica quem fará uso dos resultados das medidas.

A norma apresenta essa tabela como referência. Ao ser utilizada deve haver a sua adaptação para a aplicação em que será usada. Um exemplo dessa tabela é apresentado na Tabela 2.1 a seguir.

\begin{tabular}{|l|l|}
\hline Exemplo de métrica de satisfação & \\
\hline Nome da métrica & Questionário de satisfação \\
\hline Objetivo da métrica & $\begin{array}{l}\text { Quão satisfeito está o usuário com } \\
\text { características específicas do } \\
\text { software? }\end{array}$ \\
\hline Método de aplicação & Testes com usuários \\
\hline Medidas, fórmulas e dados & $\begin{array}{l}\mathrm{X}=\Sigma\left(\mathrm{A}_{\mathrm{i}}\right) / \mathrm{n} \\
\mathrm{A}_{\mathrm{i}}=\text { resposta a uma questão } \\
\mathrm{n}=\text { número de respostas }\end{array}$ \\
\hline Interpretação de valores & $\begin{array}{l}\text { Comparar com valores anteriores ou } \\
\text { com a média da população }\end{array}$ \\
\hline
\end{tabular}




\begin{tabular}{|l|l|}
\hline Tipo de escala & Ordinal \\
\hline Tipo de medida & $\begin{array}{l}\text { A }=\text { contável } \\
X\end{array}=$ contável \\
\hline Medidas de entrada & $\begin{array}{l}\text { Relatório de operação (testes) } \\
\text { Monitoração do uso (gravação) }\end{array}$ \\
\hline Fase em que pode ser aplicada & - Validação \\
& - Teste de qualificação \\
& - Operação \\
\hline Público alvo & - Usuário \\
& - Projetista da interface \\
& - Desenvolvedor \\
\hline
\end{tabular}

Tabela 2. 1 - Exemplo de métrica apresentada na norma ISO 9126-4

As métricas de qualidade em uso ainda são divididas em: métricas de eficiência, métricas de produtividade, métricas de segurança e métricas de satisfação. A relação entre os tipos de métrica e as perguntas que precisam ser respondidas na avaliação estão na tabela 2.2 a seguir.

\begin{tabular}{|c|c|}
\hline Tipo de métrica de qualidade em uso & Objetivos da métrica \\
\hline \multirow{3}{*}{$\begin{array}{l}\text { Métrica de eficiência (effectiveness } \\
\text { metrics) }\end{array}$} & $\begin{array}{l}\text { Qual a proporção de tarefas cujos objetivos } \\
\text { foram atingidos corretamente? }\end{array}$ \\
\hline & Qual a proporção de tarefas completadas? \\
\hline & Qual a freqüência de erros? \\
\hline \multirow{5}{*}{$\begin{array}{l}\text { Métrica de produtividade (productivity } \\
\text { metrics) }\end{array}$} & $\begin{array}{l}\text { Quanto tempo demora para completar a } \\
\text { tarefa? }\end{array}$ \\
\hline & Quão eficientes são os usuários? \\
\hline & Relação custo benefício da tarefa \\
\hline & $\begin{array}{l}\text { Qual a proporção do tempo que o usuário } \\
\text { está executando ações produtivas? }\end{array}$ \\
\hline & $\begin{array}{l}\text { Quão eficiente é o usuário se comparado } \\
\text { com um usuário experiente? }\end{array}$ \\
\hline $\begin{array}{c}\text { Métricas de segurança (safety } \\
\text { metrics) }\end{array}$ & $\begin{array}{l}\text { Qual a incidência de problemas de saúde } \\
\text { entre os usuários do produto? }\end{array}$ \\
\hline
\end{tabular}




\begin{tabular}{|c|c|}
\hline & $\begin{array}{l}\text { Qual a incidência de danos causados a } \\
\text { pessoas afetadas pelo uso do sistema? }\end{array}$ \\
\hline & Qual a incidência de danos econômicos? \\
\hline & $\begin{array}{l}\text { Qual a incidência de corrupção de } \\
\text { software? }\end{array}$ \\
\hline \multirow{3}{*}{$\begin{array}{c}\text { Métricas de satisfação (satisfaction } \\
\text { metrics) }\end{array}$} & Quão satisfeito está o usuário? \\
\hline & $\begin{array}{l}\text { Quão satisfeito está o usuário com } \\
\text { funcionalidades específicas do software? }\end{array}$ \\
\hline & $\begin{array}{l}\text { Qual a probabilidade dos usuários optarem } \\
\text { por usar o sistema? }\end{array}$ \\
\hline
\end{tabular}

Tabela 2. 2 - Objetivos dos tipos de métricas, baseado na norma IEC 9126-4

\subsection{Desafios da avaliação de usabilidade situada}

Sabe-se que para a realização deste estudo alguns desafios precisam ser contornados. Na literatura, em artigos publicados recentemente, encontram-se experimentos que enfrentaram desafios semelhantes e também algumas soluções possíveis (tabela 2.3).

\begin{tabular}{|l|l|l|}
\hline Desafios & Soluções & referência \\
\hline $\begin{array}{l}\text { heterogeneidade do } \\
\text { grupo de usuários }\end{array}$ & $\begin{array}{l}\text { grupo de foco para evitar } \\
\text { divergência na comunicação } \\
\text { (linguagem) }\end{array}$ & $\begin{array}{l}\text { EDWARDS et al. , 2006 } \\
\text { SIEK and CONNELLY, } \\
2006\end{array}$ \\
\hline $\begin{array}{l}\text { natureza crítica do } \\
\text { sistema e do ambiente } \\
\text { de teste }\end{array}$ & $\begin{array}{l}\text { planejamento levando em } \\
\text { consideração as limitações } \\
\text { do ambiente e do sistema }\end{array}$ & $\begin{array}{l}\text { EDWARDS et al. , 2006 } \\
\text { HALL, 2006 } \\
\text { SIEK and CONNELLY, } \\
\text { 2006 }\end{array}$ \\
\hline $\begin{array}{l}\text { restrições nos recursos } \\
\text { (materiais e humanos) }\end{array}$ & $\begin{array}{l}\text { planejamento detalhado } \\
\text { para aproveitar os recursos } \\
\text { da melhor forma possível } \\
\text { acompanhamento do } \\
\text { andamento do experimento } \\
\text { para redirecioná-lo, se }\end{array}$ & EDWARDS et al. , 2006 \\
\hline
\end{tabular}




\begin{tabular}{|l|l|l|}
\hline & $\begin{array}{l}\text { necessário, o mais breve } \\
\text { possível }\end{array}$ & \\
\hline $\begin{array}{l}\text { restrição nos métodos } \\
\text { de captura de dados } \\
\text { (impossibilidade de } \\
\text { utilizar gravação de } \\
\text { vídeo ou áudio) }\end{array}$ & $\begin{array}{l}\text { desenvolver formas } \\
\text { dadornativas de gravação de }\end{array}$ & HALL, 2006 \\
\hline $\begin{array}{l}\text { uma única técnica não } \\
\text { fornece as respostas } \\
\text { para todas as } \\
\text { perguntas }\end{array}$ & utilizar uma combinação de & BERNHAUPT, 2006 \\
\hline
\end{tabular}

Tabela 2. 3- Desafios e possíveis soluções

\subsection{Considerações sobre as técnicas de avaliação de usabilidade}

O que se pode concluir do estudo das técnicas de avaliação de usabilidade é que para fazer uma avaliação consistente de usabilidade em equipamentos médicos é preciso lançar mão de um conjunto de técnicas de avaliação, pois não existe uma única que possa apontar todos os problemas de usabilidade. Outra conclusão é que para contornar os desafios que podem ser encontrados em campo é necessário fazer um planejamento detalhado e completo do experimento, evitando assim o desperdício de recursos (material, humano e tempo) e não comprometendo a segurança dos pacientes ou dos usuários durante o experimento. As técnicas que se pretende utilizar daqui para frente neste trabalho, já foram utilizadas em situações semelhantes com êxito.

As métricas apresentadas na norma ISO 9126-4 se mostraram adequadas para guiar o estudo, tanto para o planejamento do experimento, como para a análise dos resultados obtidos. Essas métricas serão retomadas no capítulo 4 deste trabalho. 


\section{Ergonomia e avaliação situada}

Neste capítulo espera-se encontrar na Ergonomia as técnicas adequadas para realizar uma avaliação situada em vez de uma avaliação em laboratório.

\subsection{Ergonomia}

Ao longo da história, pode-se encontrar diversas definições para ergonomia. Rozestraten(2005) cita em seu trabalho essas definições:

- Em 1965, para Murrel, a ergonomia pode ser definida como o estudo científico das relações entre o homem e o seu ambiente de trabalho.

- Em 1968, Grandjean afirma que a ergonomia é uma ciência que compreende a fisiologia, a psicologia do trabalho, a antropometria e a sociedade no trabalho. O objetivo prático da Ergonomia é a adaptação do posto de trabalho, dos instrumentos, das máquinas, dos horários, do meio ambiente às exigências do homem

- Em 1972, para Leplat, a ergonomia é uma tecnologia e não uma ciência, cujo objeto é a organização dos sistemas humano-máquina

- Em 1975, Wisner coloca a ergonomia como o conjunto de conhecimentos científicos relativos ao homem e necessários a concepção de instrumentos, máquinas e dispositivos que possam ser utilizados com o máximo de conforto e eficácia.

Hoje, a Associação Brasileira de Ergonomia (ABERGO, 2004) utiliza a definição adotada em agosto de 2000 pela Associação Internacional de Ergonomia (IEA):

"A Ergonomia (ou Fatores Humanos) é uma disciplina científica relacionada ao entendimento das interações entre os seres humanos e outros elementos ou sistemas, e à aplicação de teorias, princípios, dados e métodos a projetos a fim de otimizar o bem estar humano e o desempenho global do sistema."

\subsection{A análise ergonômica do trabalho (AET)}

Para observar o trabalho em sua totalidade, a ergonomia utiliza-se de uma metodologia de intervenção própria: a Análise Ergonômica do Trabalho (ABRAHÃO e PINHO, 1999). 
Esta metodologia comporta cinco etapas de importância e de dificuldade diferentes em cada aplicação (WISNER, 1975):

1. análise da demanda e proposta de contrato;

2. análise do ambiente técnico, econômico e social;

3. análise das atividades e da situação de trabalho e restituição dos resultados;

4. recomendações ergonômicas;

5. validação da intervenção e eficiência das recomendações

A análise da demanda tem como meta compreender bem a natureza e o objetivo do pedido. Segundo Vidal(2002), podemos ver vários de tipos de demandas distintas :

- demandas trabalhistas, quando parte dos poderes públicos;

- demandas de certificação em qualidade (ISO, por exemplo), responsabilidade social, de medicina e segurança do trabalho e mesmo em modernos sistemas integrados de gestão;

- demandas de modernização ou de transferência de tecnologia, onde as duas demandas anteriores se combinam numa busca de excelência produtiva.

No caso de equipamentos médicos, pode-se dizer que a demanda é de modernização, provocada pela empresa produtora do equipamento. Espera-se que a análise ergonômica possa contribuir para o desenvolvimento de novos equipamentos médicos, ou para o aprimoramento dos equipamentos existentes, que estejam mais adequados ao trabalho dos profissionais da saúde. No Brasil, ainda não existe a exigência de certificação de fatores humanos para equipamentos médicos, apenas os ambientes precisam de certificação. No entanto, em países da Europa, Estados Unidos e Japão, a exigência de certificação em fatores humanos pode demandar intervenções desta natureza.

Ainda de acordo com Vidal (2002), na etapa de análise do ambiente técnico, econômico e social da situação de trabalho verificam-se as condições de trabalho. Analisa-se o tipo de tecnologia que está sendo usada (as tecnologias utilizadas estão ultrapassadas?), a situação financeira da empresa (as alterações estão acontecendo porque há recursos ou apesar da falta de recursos há a necessidade 
de alterações?) e as relações entre os funcionários e entre a empresa e o funcionário (de quem partiu a necessidade? dos funcionários ou da empresa?).

A análise das atividades e da situação de trabalho está associada a observação dos comportamentos (o que foi feito) e a explicitação de seus determinantes (porque foi feito).

Depois dessas etapas é indispensável validar o trabalho de análise através de discussões com os trabalhadores, a fim de :

- restituir a informação a quem a forneceu;

- corrigir e completar o trabalho do ergonomista.

Com essas etapas concluídas, resta ao especialista em ergonomia, com base nos resultados obtidos, elaborar as recomendações necessárias. O procedimento proposto por Daniellou (apud WISNER, 1987) implica um modo de participação do ergonomista na concepção do dispositivo ao mesmo tempo mais intenso e diferente dos costumes habituais; não se trata apenas de formular uma lista de recomendações:

- é preciso organizar e alimentar uma reflexão entre planejadores e usuários, operários e diretores;

- trata-se de um processo interativo de melhoramentos sucessivos das características do dispositivo;

Os aspectos que dizem respeito às atividades dos trabalhadores devem ser considerados muito mais precocemente e até provocar a realização de protótipos e de dispositivos parciais de teste.

Em uma última etapa do processo, a intervenção e a eficiência das recomendações são verificadas.

\subsection{Técnicas}

A Ergonomia utiliza técnicas científicas para observar o trabalho humano, entre elas as descritas a seguir:

- observação: com base nos problemas a serem observados, o especialista em ergonomia dirige suas observações e filtra as informações disponíveis 
- observação assistida: difere da observação no registro de dados; já se sabe que tipo respostas serão obtidas, dessa forma a coleta de dados pode ser feita em uma ficha de registro, por exemplo, e permite que se faça um tratamento estatístico

- registros automáticos: registro de áudio e vídeo; permite recuperar informações

- direção do olhar: a posição da cabeça e orientação dos olhos do indivíduo permite inferir para onde esse está olhando.

- comunicações: a troca de informação entre indivíduos no trabalho podem ter diversas formas: verbais, documentais e através de gestos. Traz informações sobre a aprendizagem, competência e contribuições de cada um na resolução de incidentes.

- posturas: as posturas constituem um reflexo de uma série de imposições da atividade a ser realizada. A postura é influenciada pelas características antropométricas do operador e características formais e dimensionais dos postos de trabalho.

- questionários: as respostas dos questionários podem ser úteis para a contribuição de uma classificação de tarefas e de postos de trabalho. $O$ questionário, entretanto, deve respeitar a amostra e as probabilidades de aplicação. Uma forma consolidada de elaborar o questionário é basear-se no Critérios Ergonômicos de Bastien e Scapin (1993).

- entrevistas e verbalizações provocadas: expressão direta dos processos cognitivos utilizados pelo operador para realizar uma tarefa. A entrevista pode ser consecutiva à realização da tarefa (pede-se ao operador para explicar o que ele faz, como ele faz e porque).

- entrevistas e verbalizações simultâneas: as entrevistas podem ser realizadas simultaneamente à observação dos operadores trabalhando em situação real ou em simulação.

\subsection{Considerações gerais sobre os métodos da ergonomia}

A Ergonomia é uma ciência situada, uma vez que analisa o trabalhador em seu contexto de trabalho. Por essa razão, buscou-se na Ergonomia uma metodologia que desse as diretrizes para realizar uma avaliação situada. 
A AET mostrou-se adequada aos objetivos. Adaptando o método aos propósitos do trabalho, tem-se:

- análise da demanda: determinar que equipamento vai ser analisado, determinar que tipo de respostas serão obtidas, estipular prazos e alocar recursos;

- análise do ambiente (técnico, econômico e social): conhecer o ambiente do experimento (visitá-lo se for possível), conhecer os usuários (levantamento de perfil de usuários), conhecer as relações de trabalho;

- avaliações de usabilidade (situadas): escolher as técnicas adequadas e estabelecer um protocolo de avaliação e realizá-lo;

- recomendações de projeto (estabelecimento de novos requisitos de projeto): analisar os resultados e baseado neles propor alterações e melhorias;

- validação da intervenção (verificar com os envolvidos a validade da análise): confrontar os resultados obtidos com os determinados na fase de análise da demando e se for o caso voltar para a fase de análise de usabilidade para aplicar outras técnicas ou alterar o protocolo de avaliação. 


\section{Estratégia para a avaliação situada de usabilidade em equipamentos médicos}

Neste capítulo é apresentada a proposta do método a ser empregado para a avaliação situada de usabilidade e o resultado esperado de sua aplicação.

\subsection{Teste situado}

Conforme apresentou-se no Capítulo 3, a AET pode ser decomposta nas seguintes etapas: análise da demanda, análise do ambiente (ambientes, perfil de usuário e tarefas), avaliação de usabilidade, análise dos resultados e recomendações e validação do procedimento.

A avaliação de usabilidade proposta para este trabalho emprega as seguintes técnicas: entrevistas individuais, questionários, cognitive walkthrough, entrevista em contexto e observação.

Com base nestes dois métodos de avaliação de um produto e de seu uso, estrutura-se uma técnica de avaliação situada de usabilidade, que se chamará de teste situado.

O teste situado é o conjunto de técnicas de avaliação aplicado no ambiente de uso para realizar uma avaliação de usabilidade situada. É um teste, no sentido de um experimento com usuários reais. É situado porque abre mão do controle de algumas variáveis, como os realizados em laboratório, para observar a influência do ambiente no uso do equipamento pelo usuário.

Como as demais avaliações de usabilidade, o teste situado é feito seguindose as etapas de planejamento, aplicação e análise dos dados (figura 4.1). 


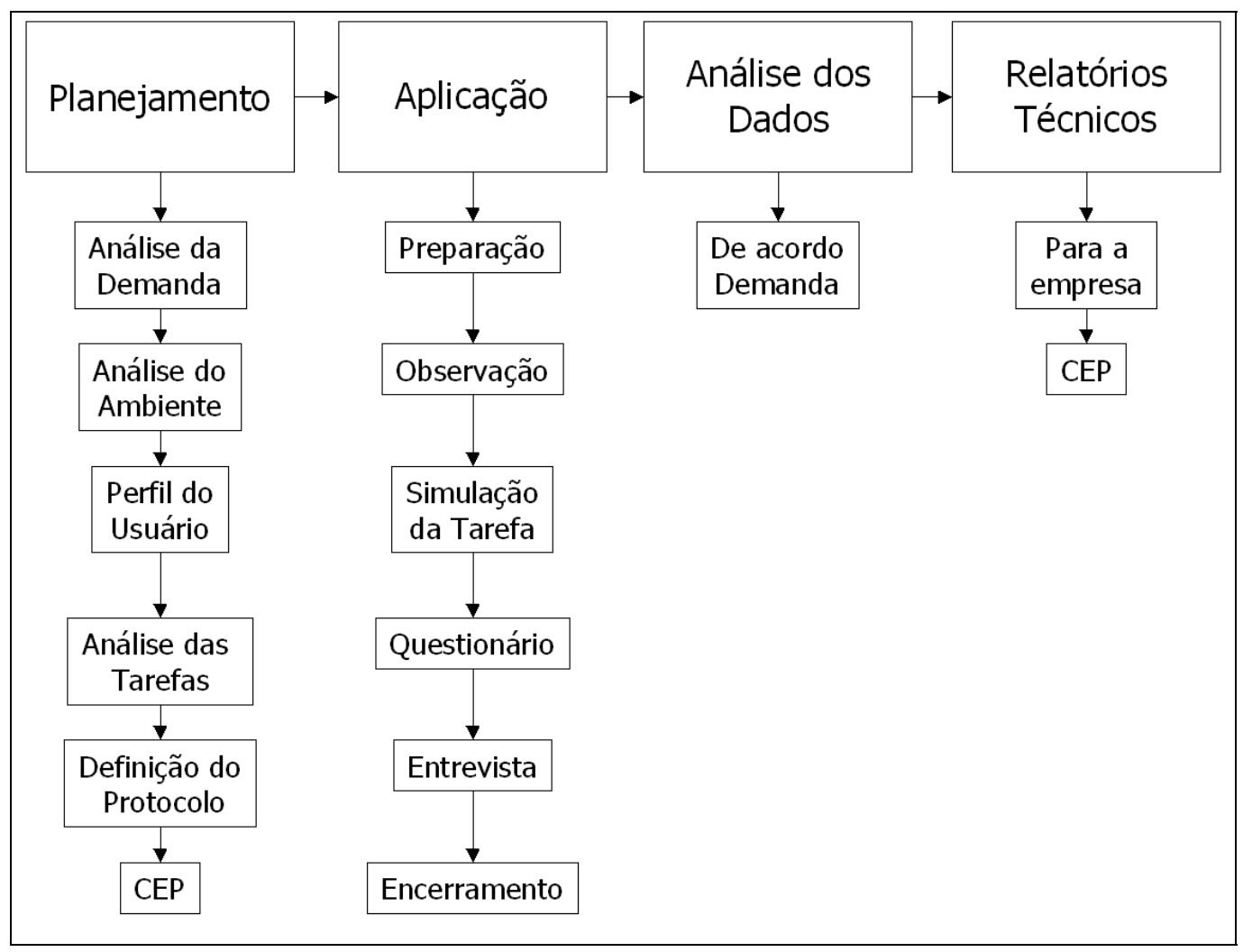

Figura 4.1: Etapas do Teste Situado

A seguir, apresentam-se essas etapas, detalhando-se a atividade do analista de usabilidade em cada uma.

\subsection{Planejamento}

$\mathrm{Na}$ etapa de planejamento do teste, a principal diferença para um teste de usabilidade é a necessidade de análise das circunstâncias nas quais o teste terá que ser realizado.

O planejamento pode ser dividido nas seguintes etapas: análise da demanda, análise do ambiente, perfil de usuário, análise das tarefas e definição do protocolo.

\subsubsection{Análise da demanda}

A análise da demanda consiste em estabelecer qual o tipo de resposta se espera obter, além de avaliar o equipamento a ser estudado, conhecer suas funcionalidades e elencar possíveis fontes de problema.

Nesta etapa é preciso entender qual é o tipo da demanda, ou seja, se é uma demanda de modernização, de certificação ou trabalhista e também identificar a fase 
do ciclo de vida do projeto. É preciso identificar também de onde partiu a demanda; se partiu do fabricante pode indicar uma constante preocupação com a melhoria, se partiu do cliente pode indicar que existem problemas graves a serem resolvidos.

A partir da análise da demanda são traçados os objetivos da avaliação, ou seja, prazos e metas.

\subsubsection{Análise do ambiente}

À análise da demanda segue-se a análise do ambiente. O objetivo desta etapa é estabelecer as variáveis do ambiente que podem ter influência no teste e que deverão ser observadas pelo analista em campo.

Por se tratar de um experimento realizado em campo, o contexto deve ser considerado no seu desenvolvimento. O contexto, além de outros atributos é composto por: usuários, ambiente, conjunto de equipamentos e características próprias do trabalho (como os pacientes no caso de um hospital ou o ruído de conversas paralelas em uma sala de telemarketing).

Nesta etapa é feito um levantamento das variáveis de ambiente, tais como disposição dos equipamentos, mobiliários, iluminação e outros aspectos que sejam relevantes para o objeto em estudo. Para esta etapa podem ser usadas visitas ao local de uso, plantas, fotos, maquetes e caso o local não esteja disponível, pesquisa em livros e revistas sobre o ambiente em questão.

Para a coleta dessas informações deve-se criar um instrumento para a inclusão de dados dessa natureza durante o experimento.

\subsubsection{Perfil do usuário}

Conhecido o ambiente, passa-se para a etapa seguinte: levantamento do perfil do usuário. O objetivo é traçar hipóteses, no teste, sobre a influência do perfil do usuário nas questões que se deseja avaliar, e produzir um instrumento que identifique um usuário real dentro destas hipóteses.

Existem diversas técnicas que podem ser usadas nesta etapa, como por exemplo aplicar questionários de perfil aos usuários, entrevistas com pessoas que conheçam os usuários, grupos de foco entre outras técnicas. 
Sabe-se que o conhecimento prévio do usuário e suas experiências influenciam o seu comportamento diante do equipamento (LIU et al. 2004); portanto os usuários consultados durante o experimento deve ser um conjunto representativo da população real de usuários. Durante o planejamento número de sujeitos a serem utilizados na pesquisa deve ser estipulado. A escolha dos sujeitos é feita aleatoriamente, procurando-se manter a proporção de cada tipo de usuário no experimento semelhante à proporção real.

\subsubsection{Análise das tarefas}

O próximo passo é identificar quais são as tarefas desempenhadas pelos usuários com o equipamento. O objetivo desta etapa é escolher um conjunto de tarefas, que serão realizadas pelos usuários reais dentro do ambiente real, que serão alvo do teste.

Novamente podem ser usadas técnicas como entrevistas, leitura dos manuais de operação e observação.

Para se escolher o conjunto de tarefas a ser testado, pode ser usado como auxílio os critérios de Rubin (1994): maior freqüência de uso, criticidade da informação para as tarefas dos usuários e conhecimento prévio da equipe de projeto sobre situações de baixa usabilidade.

É preciso escolher as tarefas que sejam mais evidentes, seja pela freqüência de uso, seja pela freqüência dos erros e falhas relacionados. Para estas, em geral, os requisitos de usabilidade são diferentes.

As tarefas de uso freqüente são importantes, em um estudo de usabilidade, porque são aquelas em que o impacto de melhorias será o mais aparente. As tarefas realizadas freqüentemente impõem requisitos de eficiência e operabilidade. No campo, estas são as tarefas mais facilmente observáveis.

As tarefas críticas são aquelas em que a má usabilidade e erros do usuário podem ter impacto significativo na missão do produto. Estas tarefas nem sempre são freqüentes e pode ser mais difícil que elas sejam observadas em campo. Entretanto, por sua natureza crítica e ocasional, essas tarefas podem exigir atributos de inteligibilidade e facilidade de aprendizado, além de baixas taxas de erros.

Finalmente, para aquelas tarefas já reconhecidamente problemáticas, não é possível estabelecer a priori os atributos de usabilidade necessários, como nos 
demais casos, mas elas podem ser justificativa suficiente para a realização de testes em campo.

Identificar as tarefas que serão alvo do teste é portanto necessário para o planejamento do teste. Conhecer o equipamento e suas funcionalidades contribui bastante para esta etapa.

\subsubsection{Definição do protocolo}

Definidos os objetivos, conhecidos o ambiente, o equipamento, os usuários e as tarefas, deve-se estabelecer um protocolo de pesquisa, que é um roteiro da pesquisa de campo.

Neste momento é estabelecida a meta do teste, e são escolhidos os locais em que o teste será aplicado e as sessões de teste.

Para compor a técnica do teste situado, foram escolhidas dentre as técnicas de usabilidade aquelas que auxiliam no alcance dos objetivos estabelecidos e que ao mesmo tempo, que possam ser aplicadas ao ambiente de estudo, pois os ambientes podem ter restrições, como é o caso de ambientes hospitalares em que o uso de gravadores, tanto de vídeo como de áudio, não são permitidos, ou seu uso é bastante restrito.

Compõem o teste situado, portanto:

- Entrevistas em contexto, em que se busca identificar dificuldades específicas dos usuários

- Uma sessão de cognitive walkthrough aplicada com uma simulação de tarefa

- Observações das tarefas com o equipamento, buscando indícios para validar o resultado das entrevistas e encontrar outros aspectos que não tenham sido citados

- Questionários para avaliar aspectos subjetivos, como a satisfação.

A aplicação conjunta destas técnicas possibilita a avaliação em campo, identificando as dificuldades do usuário com o equipamento, nas tarefas selecionadas e mesmo em tarefas relevantes que não tenham sido selecionadas, identificar as causas dessas dificuldades (projeto, treinamento, experiência ou outros), identificar possíveis novas funcionalidades e verificar a satisfação do usuário com o uso do equipamento. 
Para a elaboração do roteiro de teste, o primeiro passo é postularem-se as questões específicas que o teste visa responder. Estas questões podem ter sido obtidas de diversas formas, dependendo do estágio do conhecimento sobre a operação do equipamento: no caso de um equipamento já disponibilizado aos usuários, podem ser questões levantadas na etapa de treinamento, quando instrutores observam as maiores dificuldades de seus treinandos; podem ser resultantes de perguntas freqüentes nos serviços de atendimento ao cliente ou mesmo surgidas nas próprias observações dos clientes ou do fabricante a respeito do uso do produto. Já quando se trata de um produto novo, ainda não avaliado ainda que informalmente pelos usuários, é importante que a análise de tarefas identifique as questões relevantes para o projeto.

Independente da fonte das questões, um teste situado, assim como os demais testes de usabilidade, precisam ter um objetivo específico, algo que se quer medir com o experimento. Este objetivo deve se refletir no protocolo de pesquisa e em seus instrumentos, que devem ser exatos e bem descritos, permitindo ao analista, em campo, a coleta dos dados relevantes. Do contrário, a variabilidade do ambiente pode confundir o avaliador de usabilidade e impedir qualquer conclusão sobre os resultados. Apesar deste rigor, o protocolo do teste situado tem que deixar espaço para anotações de situações relevantes, porém não previstas, que capturem a interferência do ambiente nas variáveis de interesse.

Assim, em termos gerais, as seguintes perguntas devem ser traduzidas no protocolo de teste:

- As funcionalidades apresentadas pelo equipamento atendem às necessidades desse usuário?

- Quando o usuário não usa uma funcionalidade, é porque ela é difícil de usar, ou porque ela é desnecessária?

- A experiência de uso do equipamento é positiva ou negativa?

São estas questões que precisam ser respondidas com a aplicação das técnicas. Para auxiliar a encontrar as respostas, são usados os atributos de usabilidade e as métricas de qualidade em uso.

Dos atributos de usabilidade:

- understandability: capacidade de compreender as mensagens fornecidas pelo equipamento, capacidade de identificar se as condições de uso estão corretas ou se ocorreu um problema; 
- learnability: capacidade de aprender a usar o equipamento;

- operability: está relacionado a facilidade de operação do equipamento;

- attractiveness: está relacionado ao quão atrativo e/ou agradável é o equipamento para o usuário.

Das métricas de qualidade em uso:

- eficácia: para saber se o usuário consegue cumprir seus objetivos no que diz respeito ao uso do equipamento;

- produtividade: medir o tempo gasto para a realização das tarefas;

- segurança: medir o quão seguro é o equipamento, se não gera riscos ou se, pelo contrário, diminui riscos;

- satisfação: medir a satisfação subjetiva dos usuários com o equipamento.

Estas métricas são usadas para elaborar os instrumentos de pesquisa.

Nesta etapa são definidos, também, os recursos necessários para completar o estudo: definição de locais de aplicação, número de equipamentos necessários, permissões de acesso aos locais de estudo e permissões para a realização da pesquisa.

\subsubsection{Artefatos do Planejamento}

Durante o planejamento são usados artefatos que trazem as informações necessárias para que ele seja completado. Ao final, da mesma forma, são produzidos artefatos que possibilitam que esse planejamento seja seguido. Dessa forma tem-se: artefatos de entrada (usados para fazer o planejamento) e artefatos de saída (instrumentos do protocolo de pesquisa).

\subsubsection{Artefatos de entrada}

Como artefatos de entrada podem ser usados manuais de operação do equipamento em estudo, relatórios de falhas dos equipamentos, fotos do ambiente de uso, desenhos técnicos, descrição de cargo e ocupações dos funcionários e questionários de perfil e guias de entrevistas. 


\subsubsection{Artefatos de saída}

Como resultado do planejamento obtêm-se o protocolo de pesquisa e seus instrumentos, tais como questionários e outros documentos que a técnica de teste situado necessita:

- questionários sobre perfil do usuários

- formulário para coleta dos dados sobre o ambiente

- formulário para coleta de dados das tarefas

- formulário para entrevista

- questionário de satisfação do usuário

- checklist do material que o pesquisador deve levar para campo

- instruções ao pesquisador de campo, contendo regras para acesso e comportamento dentro do ambiente hospitalar, que podem incluir procedimentos de higiene e uso de equipamentos de proteção

- carta de aprovação do comitê de ética.

\subsubsection{Submissão do protocolo ao comitê de ética}

De acordo com a Resolução 196/96, só é possível realizar um experimento envolvendo seres humanos após a aprovação do comitê de ética, para assegurar que os princípios de privacidade e não maleficência serão observados. Em alguns casos, como em hospitais por exemplo, essa exigência faz parte dos procedimentos internos, ou seja, sem a aprovação de um comitê de ética em pesquisa, não existe possibilidade de realizar o experimento.

\subsubsection{Códigos de ética e ciência}

Durante a Segunda Guerra Mundial, foram realizados muitos experimentos com os prisioneiros de guerra nos campos de concentração na Alemanha. Uma delas foi realizada entre 1942 e 1943 em Dachau; e se buscava uma técnica mais rápida de aquecimento para os soldados que estavam enfrentando o frio europeu. No estudo, pessoas eram submetidas nuas a temperaturas abaixo de zero, por várias horas. Em conseqüência, muitos sofreram com a terrível dor do congelamento até a morte. Com fim da guerra, os responsáveis pela pesquisa foram levados a julgamento no Tribunal Militar Internacional de Nuremberg. 
O julgamento propiciou a elaboração do Código de Nuremberg. Nesse código pode-se perceber que começava a existir a preocupação de que a pessoa deve entender o que o pesquisador fará com ele e pode optar entre dar ou não o consentimento para participar de uma pesquisa (SMITH, 1970).

Além do caso acima, outros casos, ocorridos nos Estados Unidos, mobilizaram a opinião pública e a comunidade científica: 1) em 1963, três médicos, com aprovação do Diretor Clínico de um hospital judeu para enfermos com doenças crônicas, em Brooklin, Nova lorque, injetaram, por via subcutânea, células cancerosas viva em 22 pacientes debilitados, sem avisá-los ou aos familiares que tais células estavam sendo usadas a título de experimentação para mensurar a capacidade dos seus organismos rejeitarem células estranhas; 2) entre 1950 e 1970, em outro hospital daquela cidade, injetaram vírus de um tipo de hepatite em crianças com deficiência mental, visando a estudar a infectividade do vírus e a fisiopatologia da enfermidade; 3) de 1940 a 1972, no Tuskegee Study, em Alabama, EUA, cerca de 400 homens negros com sífilis, a maioria analfabeta, foram seguidos sem qualquer tratamento, visando estabelecer a história natural da sífilis, apesar do surgimento em larga escala da penicilina, em 1945. Esse fato só foi descoberto em 1972 (CASTILHO e KALIL, 2005).

Esse estado de mobilização levou a comunidade científica a definir regras para a pesquisa em seres humanos para que abusos como os citados acima não fossem mais cometidos. A Declaração de Helsinque foi publicada pela primeira vez pela World Medical Association (Associação Médica Mundial) em 1964. No centro da declaração está a afirmação de que "o bem estar do ser humano deve ter prioridade sobre os interesses da ciência e da sociedade". Também fornece atenção especial à importância do consentimento livre e esclarecido por escrito.

A Declaração de Helsinque foi revisada cinco vezes, a mais recente em 2001, para incluir questões de particular relevância ao tipo de pesquisas que vêm sendo conduzidas atualmente, como o uso de controles por placebo. Propõe que qualquer método novo deve ser testado em comparação com os melhores métodos profiláticos, diagnósticos e terapêuticos comprovados atuais, os chamados Gold Standards.

Voltando-se para os códigos de ética de entidades que orientam os profissionais de engenharia de usabilidade vê-se que os temas são semelhantes e todos eles visam proteger os seres humanos envolvidos na pesquisa. Em 
documentos como o Código de Conduta da UPA (Usability Professionals' Association) e o ACM (Association for Computing and Machinery) Code of Ethics and Professional Conduct e o caderno do CREA (Conselho Regional de Engenharia e Arquitetura) de conduta profissional do engenheiro são encontradas recomendações claras de que se deve preservar a privacidade dos indivíduos envolvidos bem como sua integridade física, psicológica e moral; além do compromisso de divulgar, quaisquer que sejam, os resultados de uma pesquisa.

\subsubsection{CEP (Comitê de Ética em Pesquisa)}

Para assegurar o cumprimento das regras éticas para pesquisas envolvendo seres humanos foram criados os comitês de ética em pesquisa.

O comitê de ética em pesquisa é o órgão institucional que tem por objetivo proteger o bem-estar dos indivíduos pesquisados. É um comitê interdisciplinar, constituído por profissionais de ambos os sexos, além de pelo menos um representante da comunidade, que tem por função avaliar os projetos de pesquisa que envolvam a participação de seres humanos. Ao redor do mundo também existe a formação de equipes como essa, com função semelhante. Nos Estados Unidos estes comitês são denominados de IRB (Institutional Review Board) e regulam não apenas as pesquisas médicas que envolvem seres humanos ou animais, mas, qualquer pesquisa que tenha a participação de seres humanos.

As características e atribuições dos Comitês de Ética em Pesquisa no Brasil estão contidas na Resolução 196/96 do Conselho Nacional de Saúde. Os Comitês de Ética em Pesquisa deverão ser credenciados pela Comissão Nacional de Ética em Pesquisa (CONEP) (GOLDIM e FRANCISCONI, 1995).

\subsubsection{Aspectos burocráticos}

Para realizar pesquisas em seres humanos é preciso submeter o projeto de pesquisa a um Comitê de Ética em Pesquisa. O comitê é composto por um grupo multidisciplinar que tem a incumbência de analisar os projetos e verificar se não ferem nenhuma regra ética ou se traz algum risco para os envolvidos na pesquisa. Muitas vezes eles também avaliam o mérito da pesquisa e os métodos empregados. 
Para submeter o projeto para apreciação do comitê o protocolo de pesquisa precisa estar definido, bem como os métodos de análise dos resultados.

Quando se trata de uma pesquisa dentro de um hospital, antes de enviar a documentação para o comitê de ética, é preciso ter um tutor (uma pessoa de dentro do departamento para orientar os trabalhos) e autorização do departamento ou departamentos para iniciar a pesquisa.

Para apresentar um projeto a um comitê de ética é preciso reunir alguns documentos:

- Projeto de pesquisa contendo:

o descrição da pesquisa;

o antecedentes e justificativa, registro no país de origem, em caso de drogas e dispositivos para a saúde;

o descrição de material e métodos, casuística, resultados esperados e bibliografia;

o análise crítica de riscos e benefícios;

o duração da pesquisa;

o responsabilidades do pesquisador, da instituição , do patrocinador;

o critérios para suspender ou encerrar;

o local de realização de várias etapas;

o infra-estrutura necessária e concordância da instituição;

o orçamento financeiro detalhado e remuneração do pesquisador;

o propriedade das informações;

o declaração de tornar públicos os resultados;

o declaração de uso específico do material

- Informações relativas ao sujeito da pesquisa:

o características da população, justificativa de uso de grupos vulneráveis;

o descrição de métodos que afetem os sujeitos da pesquisa;

o fontes de material, coleta específica;

o planos de recrutamento, critérios de exclusão e inclusão;

o modelo de termo de consentimento;

o como e quem irá obtê-lo;

o descrição de riscos com avaliação de gravidade; 
o medidas de proteção de risco e à confiabilidade;

o previsão de ressarcimento de gastos;

- Currículo do pesquisador principal e demais pesquisadores;

- Termo de compromisso do pesquisador com Resolução 196/96 (Folha de rosto);

- Termo de compromisso da instituição com Resolução 196/96 (Folha de rosto)

- Consentimento livre e esclarecido:

o termo em que o participante da pesquisa diz estar ciente e de acordo com os procedimentos pelos quais será submetido

- Currículo do pesquisador responsável

- Folha de rosto

o este documento é obtido através do registro do projeto no Sistema Nacional de Informações Sobre Ética em Pesquisa envolvendo Seres Humanos do Ministério da Saúde (www.saude.gov.br/sisnep).

Este projeto está cadastrado no SISNEP - Sistema Nacional de Informações sobre Ética em Pesquisa envolvendo Seres Humanos - sob o número CAAE0068.0.198.198-07.

Depois de entregar a documentação no comitê de ética é necessário aguardar a resposta positiva para iniciar o experimento. $O$ processo que os projetos seguem está descrito na figura 4.1. 


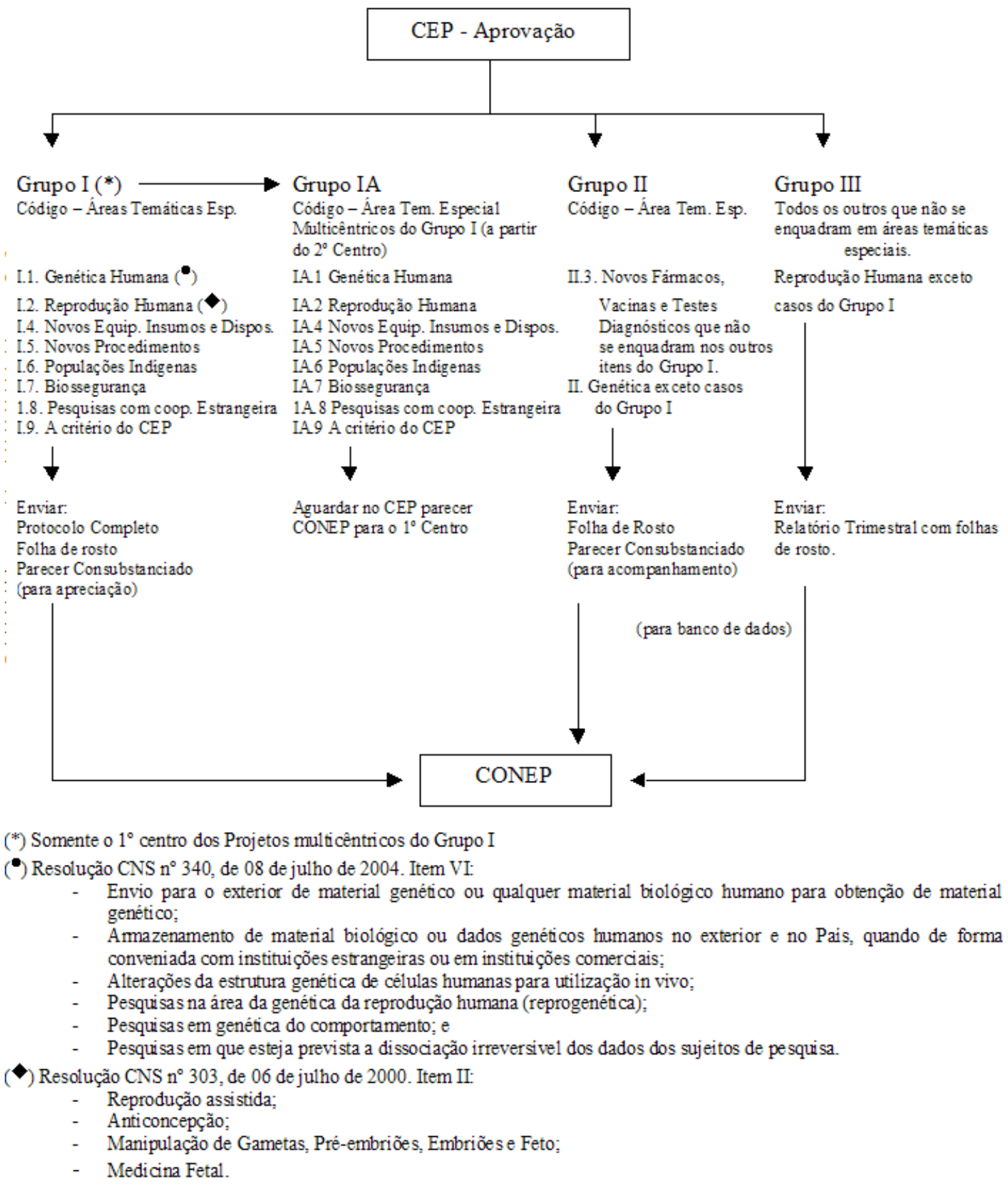

Figura 4.1: Fluxograma de Tramitação de Projetos de Pesquisa Envolvendo Seres Humanos, de acordo com as Resoluções do Conselho Nacional de Saúde.

\subsection{Aplicação do Protocolo}

A aplicação do teste situado consiste na execução do protocolo de pesquisa. Nesta etapa, é importante ressaltar que para o início da aplicação do teste, este deve estar bem estruturado, com os objetivos bem claros para o especialista. Também deve estar claro para o especialista qual o comportamento que ele deve ter 
no ambiente de estudo, visando a segurança dos envolvidos e interferir minimamente nas atividades desempenhadas no local.

Quanto aos aspectos éticos, observe-se que a aplicação do teste situado dependerá da autorização do comitê de ética, principalmente se o ambiente de uso do objeto de estudo for um ambiente de acesso restrito ou de alto risco.

Uma vez no local do teste, o avaliador aplica o protocolo, seguindo as orientações do protocolo e das regras de acesso e dos responsáveis pelo local, como por exemplo o chefe do departamento. Essas medidas devem ser tomadas para que se obtenha sucesso no estudo sem aumentar os riscos no ambiente estudado.

Assim, as seguintes etapas são realizadas na aplicação do teste: preparação, observação, simulação da tarefa, questionário, entrevista e encerramento.

Durante a preparação, o pesquisador deve reunir todos os recursos materiais necessários para a aplicação do teste seguindo o checklist elaborado durante o planejamento, ou seja, ter em mãos os artefatos de entrada dos testes, material para seu preenchimento, instrumentos de medidas (régua, fita métrica, termômetro, cronômetro, outros), em casos de ambientes de acesso restrito é importante ter uma autorização de acesso e outros itens particulares a cada caso. Nesta etapa é aconselhável entrar em contato com o responsável pelo local e agendar o horário do experimento e esclarecer quais serão as etapas do estudo.

Já no local do teste, o pesquisador faz o primeiro contato com o ambiente e com as pessoas. É importante relembrar ao responsável pelo local quais serão as atividades e de quanto tempo será a permanência. Se houver necessidade de procedimentos de higiene e/ou segurança, eles são realizados nesta etapa do experimento e sempre que houver necessidade e/ou for solicitado.

Com os instrumentos gerados na fase de planejamento inicia-se a observação. Foram definidas tarefas que se queria analisar com mais cuidado, portanto o pesquisador pode se deparar com três situações distintas: as tarefas escolhidas serem realizadas, as tarefas escolhidas não serem realizadas e serem realizadas que não haviam sido escolhidas.

Os instrumentos de observação devem ter sido construídos de forma a ser possível registrar observações de todos os tipos mencionados acima.

Com a aplicação da técnica de simulação de tarefa, é possível cobrir o caso em que as tarefas escolhidas não foram realizadas. Em um equipamento que não 
está em uso, os usuários realizam simulações das tarefas selecionadas. Observa-se cada operação realizada pelo usuário e a compara com a operação que deveria ter sido realizada. A operação "correta" é definida baseada nos manuais de operação e no projeto da funcionalidade.

A etapa seguinte consiste na aplicação do questionário de aspectos subjetivos, para avaliar a satisfação da experiência de uso dos usuários.

A entrevista é realizada para complementar as etapas anteriores. Existe um guia de entrevista (elaborado durante o planejamento) que visa coletar informações para responder as perguntas propostas no início. Porém, essa entrevista pode ser usada para tirar algumas dúvidas que surjam durante as etapas anteriores.

No encerramento pode se comunicar os resultados parciais aos envolvidos, coletar informações que não estavam explícitas, mas, se mostraram importantes durante a realização, e novamente se houver necessidade realizar os procedimentos de higiene e segurança.

Os artefatos de entrada desta fase foram produzidos na fase de planejamento. De maneira semelhante, os artefatos aqui produzidos serão usados para a análise de dados e conclusões do estudo.

Tem-se como artefatos de entrada os instrumentos da pesquisa (questionários, guias de entrevista, listas de tarefas do usuário a serem observadas, formulários e checklist) necessários para a aplicar a técnica, ou seja, os artefatos produzidos durante o planejamento.

Os artefatos de saída nesta fase são os artefatos de entrada preenchidos de acordo com o ocorrido durante o experimento.

\subsection{Análise dos Resultados}

Uma vez coletados os dados, a análise é feita de acordo com os objetivos selecionados para o teste.

Se o equipamento estiver em fase de certificação, o importante é produzir evidências de que o equipamento atende aos requisitos das normas aplicáveis.

Se o equipamento estiver em fase de revisão de projeto, o que se quer são visões sobre o uso que possam realimentar o ciclo de projeto. Neste caso, verificar o que foi feito e deu certo, o que foi feito não deu certo e o que não foi feito e fez falta. 
Os resultados da análise podem ser levados para realimentar o ciclo do projeto como recomendações e requisitos de projeto na iteração seguinte.

\subsection{Relatório técnico}

Ao final do trabalho é importante produzir os relatórios necessários, apresentando as perguntas que se buscou responder, os dados de entrada, o método usado e as respostas obtidas.

Pode-se estabelecer uma classificação dos problemas ponderando a criticidade e a freqüência, uma análise de risco dos resultados. Para a empresa, além dos resultados, podem ser incluídas nos relatórios recomendações de melhoria. Para o comitê de ética, quando houver a necessidade de entregar um relatório, essas recomendações podem ser suprimidas, mostrados apenas os resultados e sua análise. 


\section{Estudo de caso}

Visando avaliar a aplicação real da técnica de teste situado em campo, procedeu-se a uma aplicação piloto, testando-se um equipamento médico, o monitor multiparamétrico de sinais vitais.

As circunstâncias de aplicação foram favoráveis porque na DIXTAL, próximo ao final do ciclo de vida de um equipamento, ele passa por um período de validação em campo. Geralmente, essa etapa é realizada em hospitais parceiros, nos quais os devidos protocolos de pesquisa já foram submetidos ao comitê de ética. Nesses hospitais, os equipamentos de estudo já estão instalados e o acesso a quem está acompanhando a validação é facilitado.

Essa aplicação piloto foi realizada pela autora deste trabalho, embora os instrumentos tenham sido construídos de tal forma a permitir que outras pessoas pudessem realizar o experimento.

\subsection{Planejamento do teste situado}

Na etapa de planejamento do teste, a principal diferença para um teste de usabilidade é a necessidade de análise das circunstâncias nas quais o teste terá que ser realizado. É preciso analisar qual a natureza da demanda, o contexto do teste e qual resultado se quer obter.

\subsubsection{Análise da demanda}

O equipamento escolhido para estudo já está no mercado há alguns anos e encontra-se em fase de revisão de projeto, logo as respostas que se precisava obter com a avaliação, eram informações para servir de requisitos para uma nova iteração no seu ciclo de vida, ou seja, encontrar oportunidades de melhoria.

Tratava-se, então, de uma demanda provocada e também por isso as intervenções no ambiente de observação deveriam ser mínimas.

O fabricante indica o equipamento para uso em UTIs, centro cirúrgicos, unidades de pronto atendimento e outras unidades de atendimento em hospitais e clínicas médicas. A sua função é monitorar sinais vitais dos pacientes fornecendo informações sobre suas condições ao profissionais da saúde. A esses profissionais 
cabe a correta configuração, o correto posicionamento dos sensores e a interpretação das informações.

\subsubsection{Análise do ambiente}

O ambiente do estudo de caso pode ser descrito a partir das seguintes características, mas, não limitado a elas: dimensões, iluminação, ruídos, tipo de mobiliário.

Foram realizadas visitas prévias a UTIs em que o sistema estava instalado. Observou-se que os pacientes e suas doenças influenciavam no contexto de uso, pois cada enfermidade e cada tipo de paciente exigiam cuidados e tratamentos distintos. Algumas doenças exigiam, por exemplo, que o paciente fosse colocado em uma área de isolamento, o que por si só já exigia uma forma tratamento especial por parte dos profissionais da saúde em relação aos demais. Esse fator foi considerado durante a realização do experimento, decidindo-se por uma UTI geral, em que o incômodo para o paciente e o risco para a pesquisadora fossem minimizados, já que não havia motivos que justificassem outra atitude.

Dessa análise preliminar em campo, observou-se que a existência ou não de equipamentos em torno do leito do paciente também deveria ser considerada, porque muitas vezes eles eram colocados na frente do monitor, dificultando o acesso e a visualização.

Resultou desta etapa de análise do ambiente o instrumento de observação (Apêndice I), que contém um espaço destinado a anotação de informações sobre o ambiente:

- iluminação medida com luxímetro digital

- altura do equipamento, medida com fita métrica ou trena

- distância do equipamento ao leito, medida com fita métrica

- outros equipamentos ao redor do leito

Nos ambientes hospitalares os métodos de gravação são restritos. Esse tipo de procedimento é para proteger não só a privacidade dos trabalhadores, mas também a dos pacientes e outras pessoas que possam estar no local. 
Uma alternativa à gravação de dados é o registro por escrito. Apesar de não permitir que a situação seja revista e analisada por outra pessoa que não esteve presente, é uma forma simples, de baixo custo e que registra os fatos conforme o olhar do observador. No entanto, este tipo de registro demanda uma análise prévia e a confecção de um material de apoio completo e detalhado para que as informações relevantes não sejam perdidas. Essas questões foram consideradas para a elaboração dos instrumentos usados no estudo.

Para coletar essas informações, produziu-se um inventário de material para pesquisa de campo, que incluiu os seguintes itens:

- luxímetro digital

- fita métrica ou trena

- prancheta

- caneta

\subsubsection{Perfil de usuário}

Para o levantamento inicial do perfil dos usuários, foram usados como métodos entrevistas com as pessoas que conhecem os usuários e aplicação de questionários entre os usuários para determinar a formação, idade, sexo, experiência com outros equipamentos médicos entre outros.

A elaboração dos questionários de perfil, aplicados durante o teste situado, foi feita a partir das informações obtidas durante essas entrevistas, para confirmá-las ou refutá-las. O questionário aplicado encontra-se no Apêndice II.

A observação dos ambientes onde os equipamentos são usados podem dar indícios de como é a população de usuários. É possível identificar os segmentos de população e se ela é homogênea. Com essas premissas, pôde-se estabelecer uma hipótese e construir um questionário para validá-la.

No caso em estudo, por observação e uma primeira análise, a hipótese formulada era de que os principais usuários do equipamento em estudo fossem técnicos de enfermagem e enfermeiros, com idade entre 25 e 35 anos, sexo feminino, com experiência com equipamentos médicos e conhecedores dos procedimentos a serem realizados com os pacientes; geralmente trabalham em mais de um hospital. 
Para o levantamento do perfil de usuário foram aplicados questionários aos funcionários de UTIs em hospitais públicos e privados da cidade de São Paulo. O retorno dos questionários foi de $35 \%$ (foram distribuídos 100 e retornaram 35).

Confirmando a hipótese inicial o número de mulheres é superior ao de homens, $71 \%$ contra $29 \%$, como vemos na figura 5.1 .

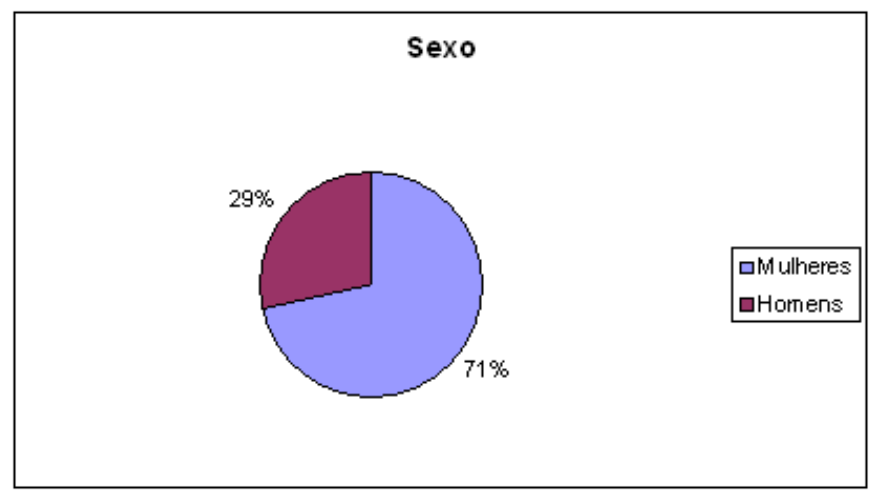

Figura 5. 1 : Distribuição de usuários de acordo com o sexo

A idade média dos usuários é de 33,5 $\pm 7,8$ anos com $8,7 \pm 6,7$ anos de experiência. Ou seja, um grupo jovem com experiência na sua área de atuação.

O maior grupo é a equipe de enfermagem, composta de enfermeiros, técnicos de enfermagem e auxiliares de enfermagem, representam cerca de $85 \%$ dos funcionários em uma UTI, como apresentado na figura 5. 2.

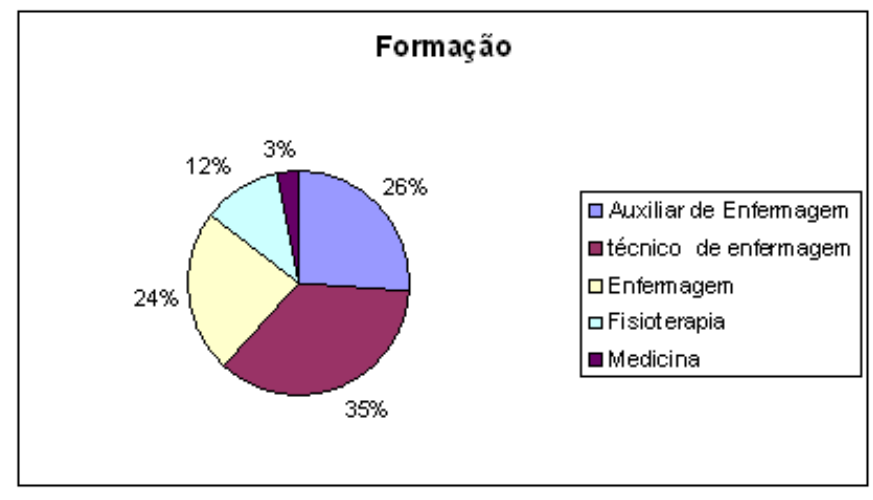

Figura 5. 2: Distribuição dos usuários de acordo com a formação

A maioria trabalha em outro hospital, cerca de $67 \%$ (figura 5. 3), e usam com freqüência computadores, tanto para o trabalho e afazeres escolares como para 0 lazer (figura 5. 4). 


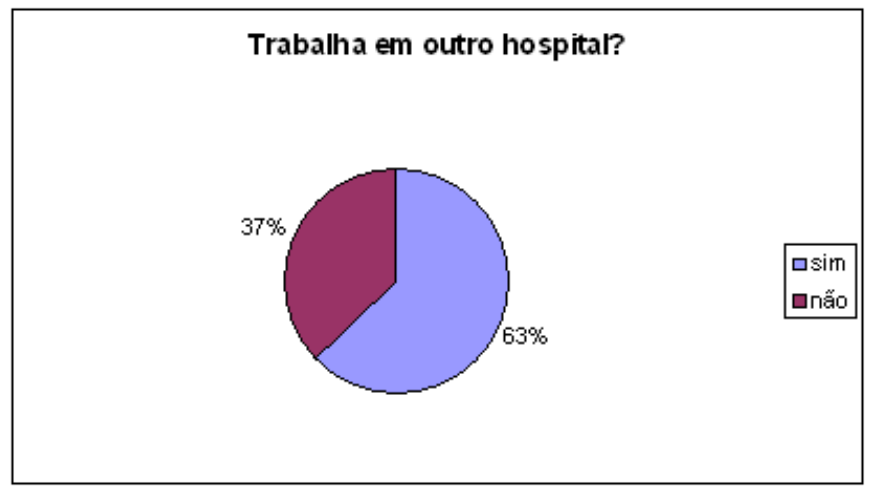

Figura 5. 3: Distribuição dos usuários de acordo com o trabalho em mais de um hospital

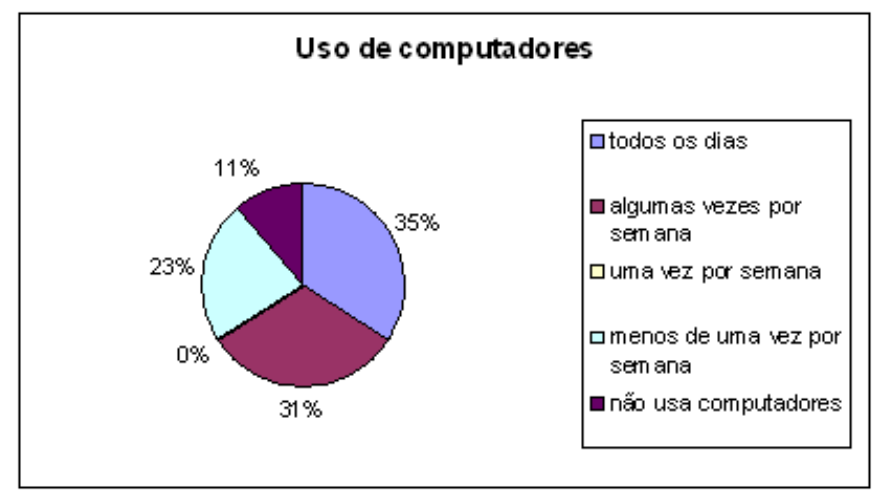

Figura 5. 4: Uso de computadores entre os usuários do equipamento

A maioria dos usuários não passou por treinamentos para aprender a usar o equipamento como aponta o figura 5.5

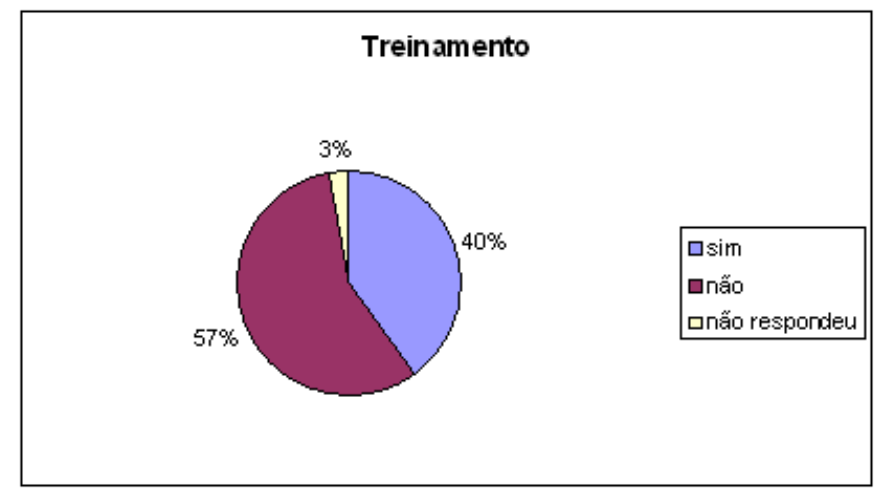

Figura 5. 5: Treinamento de usuários

\subsubsection{Análise das tarefas}

No caso em questão, as tarefas foram escolhidas de acordo com observações do equipamento tanto em laboratório como em campo (UTI e centro cirúrgicos), 
estudando o manual de operações e através do relato de usuários e de pessoas que estão em contato direto com os usuários. A tarefa freqüente selecionada foi a monitoração dos parâmetros vitais do paciente. Observe-se que uma simples observação dos parâmetros mostrados na tela do equipamento é considerada uma tarefa de uso, já que se trata de um sistema supervisório, ou seja, que fornece índices ao usuário para que ele atue no sistema, no caso no paciente. Nem sempre a tarefa interativa é dialógica.

A tarefa de natureza crítica é aquela em que se não for bem realizada pode provocar erros em outras tarefas ou aumentar os riscos ao equipamento e aos envolvidos com ele. Normalmente outras funcionalidades são dependentes desta tarefa. A tarefa de natureza crítica, selecionada é a tarefa de configuração da derivação de ECG. Na execução desta tarefa, se for escolhida uma derivação que não seja adequada, o cálculo de freqüência cardíaca pode ficar incorreto. Esta é uma tarefa menos freqüente, mas é crítica pois se não for realizada corretamente pode induzir o usuário a cometer erros, como a administração incorreta de drogas.

A tarefa de natureza problemática é aquela em já se sabe com antecedência que existem problemas. Ela pode ser selecionada de relatórios de reclamação e também por observação do equipamento em uso em laboratório ou ambiente real. A tarefa de natureza sensível selecionada no caso é a configuração de alarmes. Esta é uma tarefa que exige muito esforço do usuário e muitas vezes não é realizada de forma adequada pelo usuário (alarmes desligados ou com limites inadequados para a monitoração do paciente).

\subsubsection{Desafios e propostas para contorná-los}

Os desafios que foram encontrados antes e durante a realização do experimento são muito semelhantes aos apresentados no capítulo 2, na tabela 2.3 desta dissertação e são discutidos um a um, a seguir.

\subsubsection{Heterogeneidade do grupo de usuários}

Dentro de uma mesma unidade hospitalar, existem grupos distintos de usuários, que além de experiências distintas, têm tarefas diferentes para realizarem com o equipamento (técnicos de enfermagem, enfermeiros, fisioterapeutas e 
médicos). Entre hospitais, há uma variação nos procedimentos e na delegação de tarefas. Uma das diferenças nítidas entre hospitais da rede pública e de rede privada são os recursos . A linguagem não diverge muito nem entre hospitais e nem entre os grupos.

Para contornar este problema o experimento foi realizado com um número representativo de cada grupo de usuários e em turnos de trabalho diferentes (matutino, vespertino e noturno). A atividade no hospital é bastante diferente nos três turnos, logo as necessidades também são diferentes. O período de maior movimento na UTI é o período matutino, os pacientes são levados para realização de exames ou cirurgias, muitos procedimentos médicos são realizados neste período. Além disso, em um hospital universitário como o do experimento, é no período da manhã que aulas são ministradas.

No período da tarde essas atividades são reduzidas e é também o horário da visita dos familiares dos pacientes.

No período noturno as atividades são ainda mais reduzidas, se concentram na observação dos quadros dos pacientes e no atendimento de emergências.

Vê-se assim, que em cada período as necessidades são distintas, por isso o experimento fica mais completo com a coleta de dados em turnos diferentes.

\subsubsection{Natureza crítica do sistema e do ambiente de teste}

Os equipamentos, objetos de estudo deste trabalho, são responsáveis por fornecer informações aos profissionais da saúde sobre as condições do paciente. Muitas vezes, ele não pode ser desligado, ter suas configurações alteradas ou ter a visualização impedida, pois isso poderia trazer riscos ao paciente.

Algumas vezes, durante o experimento pode se encontrar pacientes que estejam dentro de algum tipo de isolamento, seja porque seu estado de saúde está bastante debilitado, seja porque seja portador de algum tipo de doença contagiosa.

Portanto, algumas recomendações são feitas ao especialista em usabilidade no momento de realizar o experimento:

- atender as regras de higiene do hospital onde se está realizando o experimento: lavar as mãos conforme as instruções e usar 
equipamento de segurança (luvas, avental ou touca) quando houver exigência;

- levar para o local do experimento apenas o material necessário: o mobiliário é para o aparato necessário para o cuidado com o paciente;

- todas as vezes que iniciar o trabalho avisar o chefe do departamento e explicar as atividades do dia; avisá-lo igualmente quando estiver saindo do local : esta atitude aproxima o especialista da equipe do hospital;

- evitar os horários de visita : este é um momento do paciente com seus familiares, a equipe médica também se afasta nesses momentos;

- se houver um incidente com o paciente, interromper o estudo para que ele possa ser socorrido adequadamente;

- evitar o local de experimento se estiver doente.

Seguir essas recomendações favorece o bom desenvolvimento do trabalho, pois aumenta a receptividade da equipe médica e sua colaboração, não oferece riscos para a saúde dos pacientes ou para a saúde do especialista.

Além disso, para assegurar que o experimento, mesmo que não intencionalmente, não traria prejuízos para os funcionários ou pacientes do hospital, o projeto foi submetido para apreciação ao comitê de ética.

\subsubsection{Definição do protocolo}

Definidas as tarefas que seriam observadas (visualização de parâmetros, mudança de derivação de ECG e a configuração de alarmes) e as técnicas de avaliação que seriam utilizadas foram criados os instrumentos de pesquisa (ver Apêndice I, II, III e IV) e o protocolo de pesquisa.

No Apêndice I encontra-se a ficha de observação. Ela foi desenvolvida para ajudar a captura de informações durante a observação como o número de pessoas que passaram e olharam para o equipamento e tarefas específicas, além de informações do ambiente como a intensidade luminosa e a posição (altura) do equipamento. 
No Apêndice III encontra-se o guia de entrevista que foi construído para identificar aspectos subjetivos como a satisfação com $o$ equipamento $e$ necessidades que não estão sendo atendidas pelas funcionalidades atuais.

No Apêndice IV encontra-se a ficha de observação da tarefa. Ela foi construída para identificar o percurso cognitivo dos usuários.

Para a realização do experimento foi escolhida a UTI adulto do Hospital Universitário do USP, com 10 sujeitos no período de quatro semanas, incluindo a coleta e análise de dados.

\subsubsection{Submissão do protocolo ao Comitê de Ética em Pesquisa}

Para submeter o protocolo ao comitê de ética em pesquisa, foi preciso a autorização do departamento em que seria realizado o estudo (UTI adulto).

Após análise da proposta de trabalho, o Professor Doutor Francisco Garcia Soriano concordou ser tutor deste trabalho dentro do Hospital Universitário e os responsáveis pela Clínica Médica autorizaram a continuidade do processo.

O restante da documentação foi consolidado e encaminhado para a análise. Somente após a aprovação, o experimento pôde ser realizado. O material entregue para o Comitê de Ética do Hospital Universitário da Universidade de São Paulo e as cartas de aprovação encontram-se no Apêndice V.

\subsection{Aplicação do protocolo}

Conforme a prescrição do teste situado, cada sessão de teste - no caso, cada visita à UTI - pode ser dividida nas seguintes etapas:

- Preparação;

- Observação;

- Aplicação do questionário;

- Simulação de tarefa;

- Entrevista;

- Encerramento

Descrevem-se a seguir como estas etapas foram realizadas no estudo de caso. 


\subsubsection{Preparação}

Como a UTI é um ambiente restrito, cada visita precisou ser agendada com a pessoa responsável. Além disso, devido às restrições de espaço, levava-se apenas o material que seria utilizado (lápis, os formulários, relógio, prancheta, fita métrica e o luxímetro, que é um medidor de densidade luminosa).

$\mathrm{Na}$ hora marcada, o pesquisador apresentou-se ao responsável da unidade e descreveu o procedimento que seria realizado. Realizou-se o procedimento de higiene indicado (lavar as mãos, usar luvas, avental ou máscaras, etc.).

Seguiu-se a escolha do monitor para observação. Era escolhido, preferencialmente, um monitor com paciente recém-chegado, pois a probabilidade de execução das tarefas escolhidas eram maiores. Preferiram-se também monitores que ficassem em locais onde era possível se posicionar para observação sem prejudicar a passagem das pessoas e sem atrapalhar o bom andamento das tarefas dos trabalhadores.

Com os formulários em mãos iniciou-se o experimento (os formulários que estão nos Apêndices I, III e IV).

\subsubsection{Observação}

Com o formulário de observação, foram tomadas notas das tarefas dos usuários. Foram anotadas a situação e as funções usadas no equipamento. Não era necessário anotar os procedimentos realizados com o paciente (como por exemplo banhos e curativos). Também não era necessário anotar a administração de dieta ou medicamentos. Esta etapa consumia cerca de uma hora por visita (52 minutos em média), que era o tempo disponível para as observações.

\subsubsection{Questionário}

Os questionários de aspectos subjetivos foram aplicados aos funcionários que estavam no centro de enfermagem, no período de pausa de suas atividades, durante os horários de visita e próximo ao horário de troca de turno. Eles foram aplicados junto com a entrevista. 


\subsubsection{Entrevista}

Nesta etapa foi conduzida uma entrevista baseada no roteiro. Conforme o caso, poderiam ser feitas outras perguntas e se houvesse necessidade as perguntas eram explicadas para o entrevistado. A entrevista foi feita em uma sala reservada $e$ foi gravada. O material resultante não é disponibilizado neste trabalho devido ao protocolo de consentimento, mas os resultados são apresentados a seguir na seção 5.3 .

\subsubsection{Encerramento}

Ao terminar os procedimentos, o responsável era comunicado. Novamente os procedimentos de higiene indicados eram realizados.

O período de permanência total na UTI por cada visita foi na média duas horas e cinqüenta e três minutos, tempo suficiente para realizar os procedimentos da pesquisa e também para seguir os procedimentos de higiene e segurança do hospital.

\subsubsection{Desvios do protocolo}

Durante o experimento ocorreram dois desvios do protocolo: a etapa de simulação da tarefa não foi realizada e houve a formação de um grupo de foco.

A simulação da tarefa não pôde ser realizada por falta de tempo disponível por parte dos usuários. Mesmo as entrevistas foram interrompidas diversas vezes por causa das obrigações dos entrevistados. Uma vez que a simulação da tarefa exigia mais tempo não houve oportunidade para executá-la.

O grupo de foco se formou naturalmente, a realização de uma entrevista com um funcionário, aproximou outro funcionário. Com esse grupo de foco foi possível separar o que eram afirmações do grupo e o que eram afirmações particulares de cada um.

\subsection{Resultados}

A seguir são apresentados os resultados obtidos no teste situado deste estudo de caso. 


\subsubsection{Ambiente}

As condições de ambiente em toda a amostra foi semelhante. O monitor estava sobre um suporte a uma altura de 1,57 \pm 0,03 metros, e o espaço entre o leito e o monitor era de $31,80 \pm 3,77$ centímetros.

A luminosidade estava adequada em $80 \%$ dos casos, nos demais a luminosidade estava abaixo dos limites considerados aceitáveis (de 100 a 750 lx) estabelecidos pela norma NBR 5413, mas, esse fato não prejudicava a visibilidade do equipamento. A observação em que a luminosidade encontrada era baixa, foi realizada no período noturno, em que uma parte das lâmpadas é apagada.

Em $80 \%$ dos casos havia outros equipamentos próximos ao monitor observado como ventiladores e bombas de infusão, desses, 12,5\% estavam desligados.

\subsubsection{Resultado das entrevistas}

As entrevistas foram realizadas com um grupo representativo dos usuários. Nas 10 entrevistas foram ouvidos 1 médico residente, 2 fisioterapeutas, 3 enfermeiros e 4 técnicos de enfermagem. Na UTI do Hospital Universitário da USP não trabalham auxiliares de enfermagem.

Com os resultados obtidos nas entrevistas, pode-se concluir que o tempo despendido para realizar uma tarefa com o equipamento e o tempo que se levou para aprender a executar os comandos para realizar a tarefa foi julgado como adequado pelos usuários, embora, todos os entrevistados tenham citado a falta de treinamento como um fator de prolongamento do tempo de aprendizado.

Com relação a problemas e dificuldades enfrentados com o equipamento, $42 \%$ mencionaram problemas com configuração do equipamento, como por exemplo a configuração de alarme (ajuste dos limites) e configuração da derivação de ECG. A dificuldade de usar os acessórios apareceram em $21 \%$ das reclamações, foram consideradas dificuldades a falta de acessórios, a dificuldade de conectá-los ao módulo e o funcionamento diferente do que eles esperavam. Um número igual de reclamações $(21 \%)$ foram relacionadas às funções do equipamento, ou porque não respondem como o esperado ou porque os usuários não sabe usá-las corretamente (figura 5.6). 


\section{Tipo de problemas}

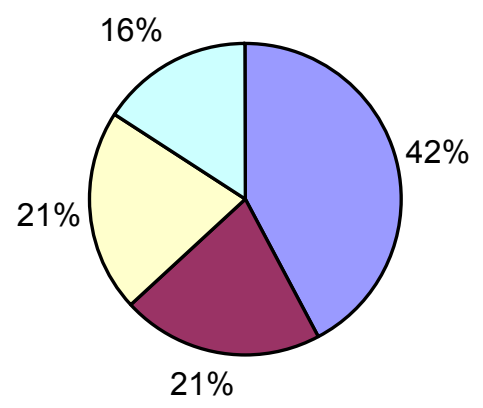

Figura 5.6: Distribuição dos problemas encontrados pelos usuários

Sobre as possíveis causas das dificuldades, todos os entrevistados apontaram a falta de treinamento como responsável pelas dificuldades. Metade dos entrevistados apontaram a falta de treinamento como a única responsável, da outra metade, $40 \%$ apontaram também que as informações não eram claras, ou a falta de informações, fornecidas pelo equipamento, como as mensagens de erro e as instruções e $60 \%$ mencionaram ainda a falta de experiência como responsáveis pelas dificuldades (figura 5.7).

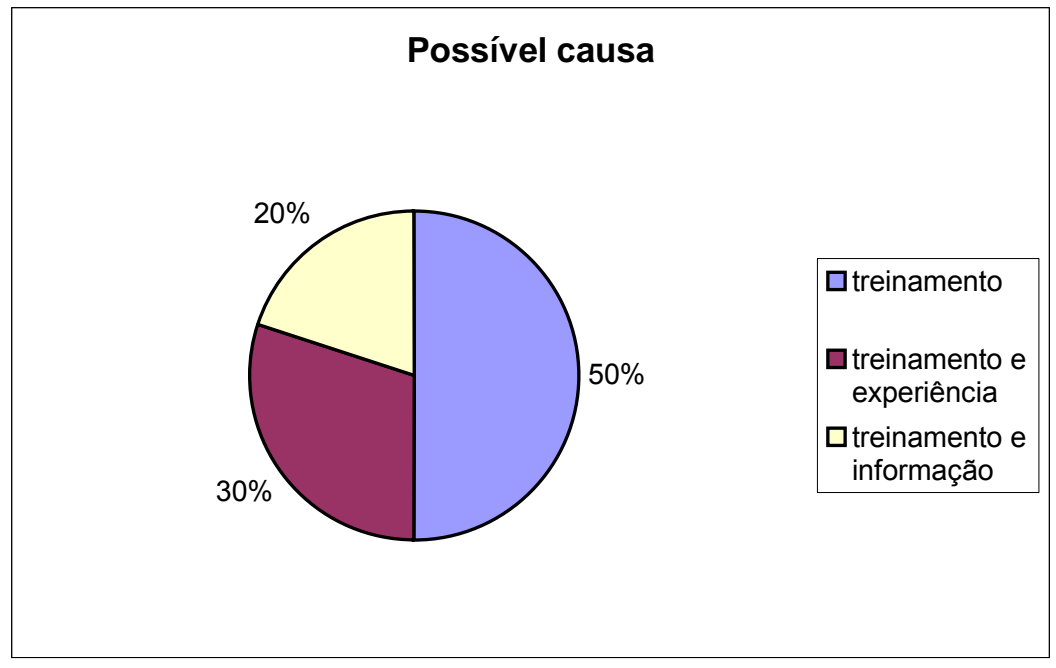

Figura 5.7: Distribuição das possíveis causas de dificuldade

Quando o assunto foi propostas de mudanças, 9\% sugeriram novas funcionalidades e $27 \%$ acharam mais interessante modificar funcionalidades existentes, como aumentar a faixa de medida de saturação para medir valores 
abaixo de $50 \%$, 37\% dos entrevistados sugeriram mudanças nos acessórios e outros $27 \%$ sentiram a necessidade de alterações específicas na interface, como o aumento do tamanho dos números na tela (figura 5.8).

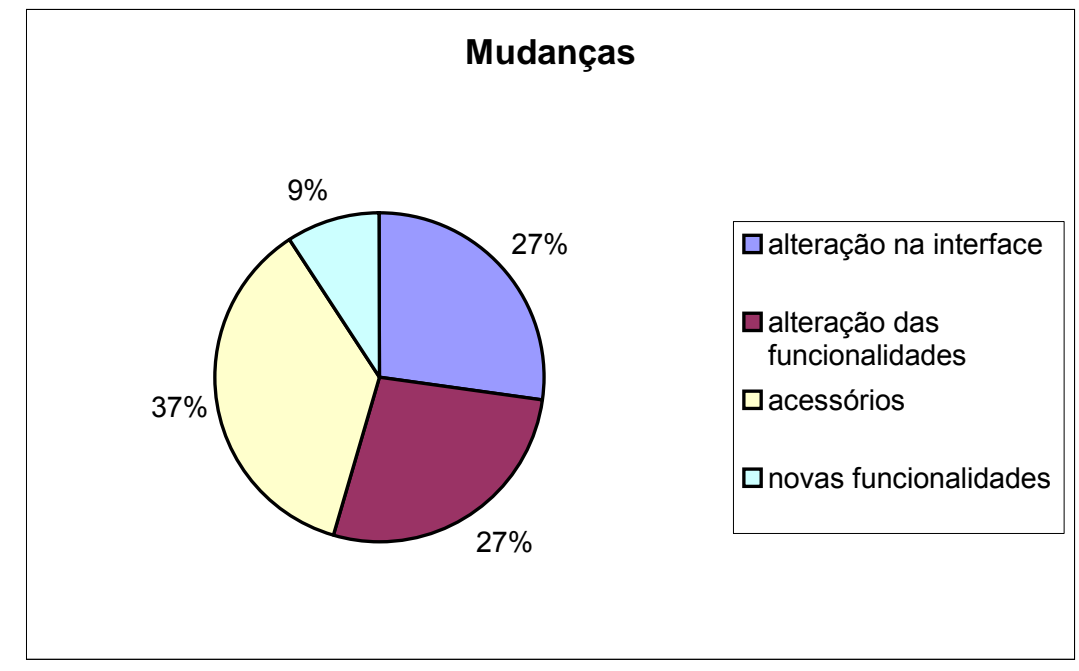

Figura 5.8: Distribuição das alterações propostas

Através desses dados pode-se concluir que ainda existem necessidades dos usuários que não estão cobertas pelas funcionalidades do equipamento.

\subsubsection{Resultado das observações}

Foram realizadas 10 observações em 10 monitores diferentes, um total de 520 minutos o que resulta em uma média de 52 minutos por observação.

Durante as observações, foi possível averiguar que em média, a cada 70 segundos uma pessoa passa pelo monitor a cada 9,8 minutos uma pessoa passa e olha, e a cada 37 minutos uma pessoa faz anotações no prontuário do paciente. Isso caracteriza o monitor multiparamétrico como de uso ocasional.

Além de monitorar os parâmetros, os usuários executam outras tarefas com o equipamento. No experimento observou-se alguns tipos de tarefas: configuração de alarmes e outras configurações (como a ativação de medidas periódicas de pressão não invasiva), análise mais detalhada do estado do paciente baseada nas informações fornecidas pelo equipamento (curvas, números e gráfico de tendência), prevenção e correção de modos de falha (não efetuar medida, não conectar os módulos corretamente, por exemplo), realização de medidas, conexão de acessórios, outras atividades que poderiam ser realizadas com o monitor e não são (medida de temperatura, por exemplo) (figura 5.9). 
A conexão de acessórios foi a tarefa executada com mais freqüência. As dificuldades envolvidas, estão relacionadas principalmente ao posicionamento do equipamento, tanto no que se refere a altura como no espaço diponível para essa atividade.

Em dois tipos de tarefas foram observados comportamentos que não eram o esperado. $O$ equipamento forneceu mensagens de erro ou alerta, mas, a mensagem foi ignorada.

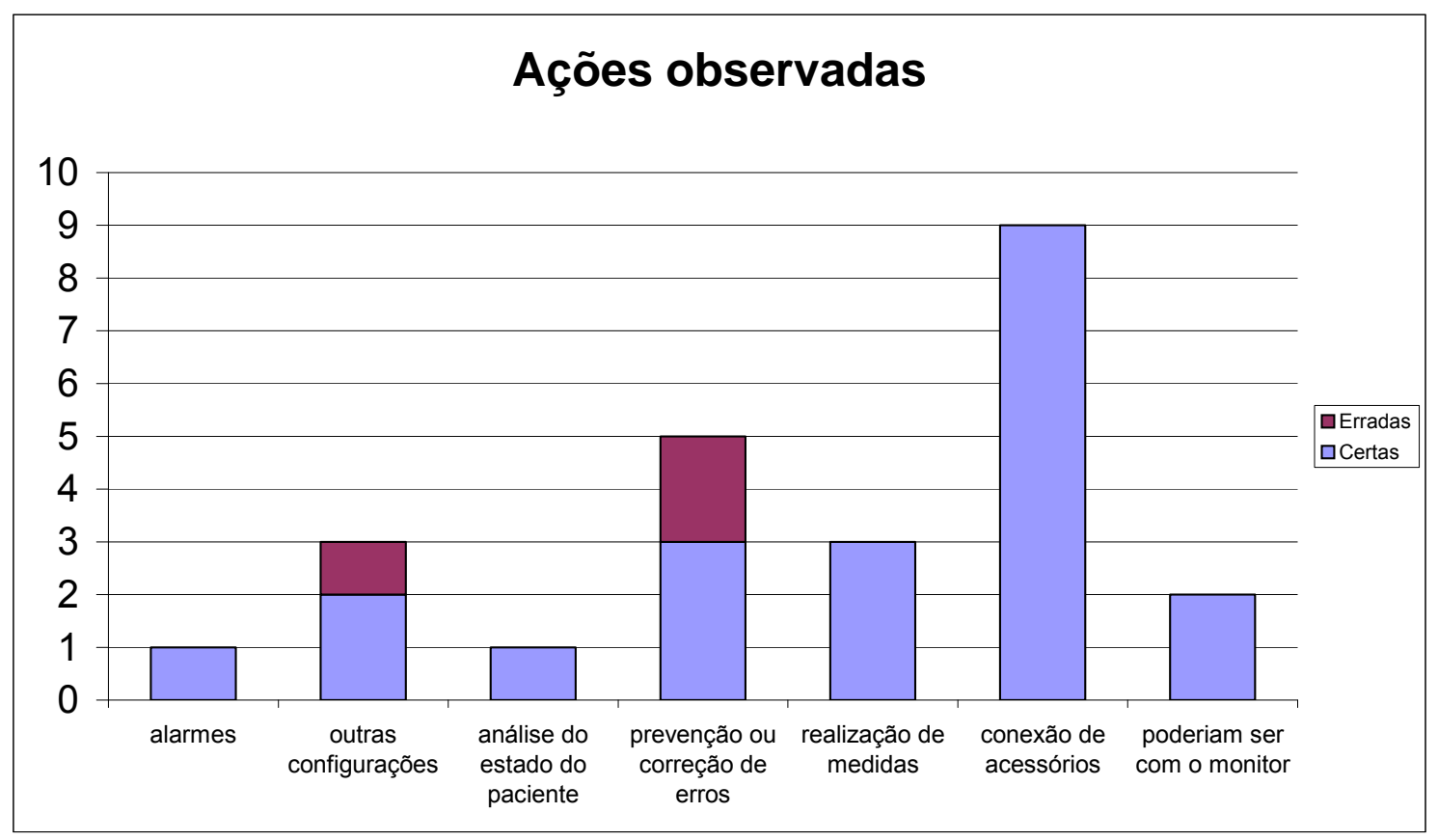

Figura 5.9: Distribuição das ações observadas

$\mathrm{Na}$ tarefa de olhar para a tela no monitor, observar os parâmetros e anotá-los não foram encontrados problemas. Apenas em um dos casos, um usuário encontrou uma dificuldade maior para enxergar os valores, mas, ele estava a uma distância maior que a habitual, inclusive para ele.

\subsection{Considerações sobre os resultados}

Através dos resultados obtidos foi possível notar que existem necessidades dos usuários que não estão cobertas pelas funcionalidades do monitor.

Como tempo é fundamental para os usuários, algumas tarefas poderiam ter seus tempos de execução reduzidos, com teclas de atalho por exemplo. Um exemplo citado de tecla de atalho foi a tecla para acionar a ajuda do equipamento. Em outros casos, as informações mais claras podem reduzir o tempo que o usuário 
precisa dedicar ao equipamento para realizar tais tarefas, como um guia para realizar o zeramento do módulo de pressão invasiva.

O posicionamento do equipamento mostrou-se um empecilho para a execução das tarefas, o que poderia ser melhorado com o desenvolvimento de suportes mais adequados e recomendações ao cliente do posicionamento e espaço mais adequados.

Com as informações obtidas nas observações e nas entrevistas, podemos concluir que algumas dificuldades encontradas pelos usuários poderiam ser minimizadas com mais treinamentos ou treinamentos específicos.

Das perguntas feitas no início, com os resultados, é possível responder a todas elas:

- As funcionalidades apresentadas pelo equipamento atendem às necessidades desse usuário?

o Atendem, embora existam oportunidades de melhoria, como a redução no tempo para iniciar o monitor, e outros fatores que têm outras origens que não o equipamento, com, por exemplo, a falta de acessórios

- Quando o usuário não usa uma funcionalidade, é porque ela é difícil de usar, ou porque ela é desnecessária?

o Foi possível identificar os dois casos: tem-se o caso dos fisioterapeutas que usam o monitor com freqüência mas, poucas funcionalidades porque o restante não lhes interessa para realizar suas tarefas e o caso dos que não usam as funcionalidades porque não sabem como usá-la, caso da medida de temperatura. Os que disseram que não usam algumas funcionalidades por não saberem usar estavam em treinamento nas suas funções.

- A experiência de uso do equipamento é positiva ou negativa?

o A satisfação dos usuários está elevada. A resposta foi positiva tanto na pergunta direta (Você está satisfeito com o equipamento?), como durante a entrevista quando eram questionados se já haviam enfrentado algum problema com o equipamento, todos iniciaram com não e só depois refletiam um pouco sobre o assunto e se lembravam de alguma dificuldade 


\section{Resultados e Conclusões}

Neste capítulo serão apresentadas as reflexões sobre os resultados obtidos e a perspectiva de futuros trabalhos.

\subsection{Discussão sobre os objetivos alcançados}

Como estabelecido nos objetivos deste trabalho, foi possível propor uma estratégia para realizar uma avaliação de usabilidade situada em equipamentos médicos. Esta estratégia foi concretizada na forma de uma técnica, o Teste Situado, que é uma combinação específica de técnicas de avaliação de usabilidade e de técnicas da Avaliação Ergonômica do Trabalho (AET).

Considerando a criticidade do ambiente hospitalar fez-se o estudo de viabilidade das técnicas e chegou-se a um conjunto de técnicas que poderiam ser usadas sem introduzir novos riscos ao ambiente de estudo e que pudessem fornecer as informações desejadas.

Ainda por conta da criticidade do ambiente estabeleceu-se um conjunto de recomendações para o pesquisador, para garantir que as regras de higiene, segurança e ética não fossem violadas.

Foram desenvolvidos artefatos específicos para apoio à execução do Teste Situado e produzidas recomendações de como alterar e manusear estes artefatos.

O Teste Situado foi ensaiado na avaliação de um monitor multiparamétrico instalado em uma UTI. Os resultados da aplicação do método serviram para aperfeiçoá-lo.

\subsection{Discussão sobre o método}

O método conseguiu obter respostas para as perguntas estabelecidas no início da pesquisa.

No início, o que se queria era verificar se as funcionalidades do equipamento atendem às necessidades do usuário, saber o motivo de um usuário não utilizar algumas funcionalidades e verificar se a experiência de uso é positiva ou negativa.

Verificou-se que existem oportunidades de melhoria mas, também foi possível identificar fatores de outras origens, como a falta de acessórios. 
As funcionalidades que não são usadas, não o são por dois motivos distintos: não existe necessidade de usá-las e não sabem usá-las. O segundo caso foi mais comum entre aqueles que estavam em fase de treinamento de suas funções.

A experiência de uso entre os que participaram da pesquisa tem sido positiva, muitos fizeram a comparação com outros tipos de equipamentos ou equipamentos similares ressaltando os pontos que lhes parecem favoráveis em relação aos outros, como as cores, por exemplo.

Estes resultados indicam que o Teste Situado tem potencial de trazer benefícios ao projeto dos equipamentos médicos.

\subsection{Observações a partir do estudo de caso}

Com o estudo de caso foi possível identificar vantagens e desvantagens na aplicação da técnica proposta, o Teste Situado.

Uma das vantagens que se pode observar sobre outras técnicas é a possibilidade de capturar informações que não seriam vistas em laboratório, pois algumas necessidades surgem apenas nas condições reais, como a dificuldade física de alcançar o equipamento provocada pelo conjunto de outros equipamentos em torno do leito do paciente. Esse fato foi considerado como influência do contexto na execução das tarefas.

Foi possível identificar as funções que não eram usadas normalmente e também distinguir as que não são usadas porque não precisam e as que não são usadas porque o usuário não sabe usá-las. Podemos citar o caso dos fisioterapeutas que não usam recursos do monitor como as medidas periódicas de pressão não invasiva porque normalmente não necessitam dessa função e o caso de um técnico de enfermagem que não habilita a detecção de respiração porque não sabe como fazê-lo.

No caso estudado, o foco dos usuários dos equipamentos era cuidar dos pacientes. O monitor multiparamétrico dentro de uma UTI funciona apenas como uma ferramenta auxiliar. Nas condições reais de uso, a pesquisadora pôde vê-lo sendo operado como um ferramenta auxiliar, enquanto que em laboratório, a principal tarefa do usuário seria o uso do equipamento, mascarando, assim, as dificuldades e facilidades de uso no contexto. 
Mesmo para as entrevistas, que poderiam ser realizadas em laboratório, 0 fato de terem sido conduzidas dentro do ambiente de uso fez diferença: os usuários podiam consultar visualmente o equipamento em operação e o próprio ambiente de trabalho e lembrar de situações que o incomodaram quando aconteceram, mas, que depois foram esquecidas.

O local possuía outros tipos de equipamentos médicos, e alguns participantes se sentiram a vontade para mostrar exemplos nesses equipamentos de como eles gostariam que fosse. Com o equipamento do estudo de caso disponível os participantes puderam mostrar ou simular as dificuldades que tinham com 0 equipamento.

Com a ASU, além de identificar deficiências de projeto e possibilidades de melhoria, é possível identificar os problemas de outras origens, também de interesse da empresa fabricante, como a falta de treinamento ou treinamento inadequado.

O próprio processo de ASU pode trazer benefícios para o projeto. É uma experiência rica que possibilita conhecer melhor o ambiente real de uso, a rotina dos trabalhadores e as atividades desempenhadas com o equipamento e ao redor dele. Essas informações tem o potencial de tornar o projeto mais adequado ao ambiente e às necessidades dos usuários.

No estudo de caso foi possível, porém, observar uma desvantagem do método. O volume de trabalho em um UTI é sazonal, mas não de periodicidade previsível. Como mencionado anteriormente, o tipo de enfermidade do paciente interfere nas tarefas dos trabalhadores e conseqüentemente no uso do equipamento, assim como o número de pessoas internadas, pois quanto mais pessoas internadas, menos tempo disponível para realizar as tarefas. Porém, como não é possível prever as alterações de volume do trabalho, algumas experiências de uso podem não ser observadas.

O risco de não observar as tarefas era previsto, por isso foi incluída no protocolo a etapa de simulação da tarefa. Mas, essa etapa não pôde ser realizada por falta de disponibilidade dos participantes. No entanto, esta etapa continua sendo considerada importante e foi mantida na especificação do Teste Situado.

Uma vulnerabilidade do método também foi observada, embora o material tenha sido construído para permitir a participação de qualquer observador, a estratégia proposta exige um conhecimento do funcionamento e da dinâmica do contexto por parte desse observador, para que seja possível fazer uma coleta de 
dados eficiente. A etapa de análise da demanda pode ser usada como uma fase de preparação do observador, mas, existe o risco da preparação não ser suficiente.

\subsection{A ASU e demandas de outra natureza}

No caso estudado a demanda era uma demanda de modernização, mas, ela poderia ser aplicada em outras demandas como a de certificação e trabalhista.

Com a técnica seria possível gerar evidências de atendimento às normas. Para isso, na etapa de planejamento e criação dos instrumentos de pesquisa as perguntas a que se deve responder devem vir das cláusulas das normas.

No caso em que o trabalhador esteja sofrendo problemas saúde ou tenha seu desempenho prejudicado por causa do equipamento, novamente, os objetivos estabelecidos e a criação dos instrumentos deve considerar esses fatores.

\subsection{A ASU e a empresa}

O tempo para a aplicação da ASU é relativamente longo, principalmente por causa da submissão a um CEP. Apenas esta etapa demora em média 3 meses. Para minimizar o impacto desse período para a empresa, uma alternativa é iniciar o planejamento no começo do projeto, para que as etapas de apreciação do projeto de avaliação ocorram junto com o desenvolvimento do produto.

Além disso, considerando uma amostra semelhante a feita no estudo de caso, 10 sujeitos, e tempo de aplicação de 3 horas, tem-se no final 30 horas de coleta de dados. Além do tempo de planejamento, mais 20 horas e o tempo de análise dos dados e elaboração das recomendações, mais 20 horas.

Mas, o retorno do processo é promissor, pois pode proporcionar ao produto melhorias que agradam aos usuários, atendendo suas necessidades com maior precisão, dando ao produto um diferencial em relação aos concorrentes. Além disso, fornece a oportunidade de aproximar a equipe de projeto do usuário, o que em si é uma experiência profissional de valor para outras situações de projeto.

\section{6 Ética e suas implicações neste trabalho}

Uma das questões que surgiram ao longo deste trabalho é se um estudo de usabilidade precisaria passar pela avaliação de um comitê de ética em pesquisa. 
Quando se pensa em avaliações de usabilidade de sistemas na Internet, em ambientes de trabalho ou domésticos, com pessoas ditas "normais", provavelmente não veríamos a necessidade de tal avaliação. Mas, se pensarmos em sistemas desenvolvidos para uma população sensível (pessoas com alguma deficiência, crianças, portadores de doenças mentais ou físicas, etc.) ou que sejam usados em ambientes críticos, como hospitais, que é o caso deste trabalho, hangares, ou outro ambiente que possa oferecer risco para o pesquisador ou para os envolvidos na pesquisa, é aconselhável submeter o projeto ao comitê de ética, para verificar se o projeto será realizado de forma segura e livre de constrangimentos, para todos os envolvidos, inclusive os pesquisadores.

No caso de um hospital, por exemplo, é preciso garantir que as regras de higiene e segurança sejam seguidas devidamente e que haja proteção da privacidade e saúde dos funcionários e principalmente dos pacientes e seus familiares. Como mencionado em capítulo anterior, este é um ambiente crítico.

A aprovação da pesquisa por um comitê de ética é uma forma de proteger os resultados, o pesquisador e principalmente os envolvidos na pesquisa (VIEIRA, 2005). A submissão do projeto do estudo de caso ao comitê de ética era uma exigência do hospital. Sem a aprovação do comitê de ética em pesquisa do Hospital Universitário da Universidade de São Paulo não seria possível realizar a pesquisa.

$\mathrm{O}$ que se pode questionar neste caso ou em outros estudos semelhantes que não envolvam ambientes críticos ou pessoas com necessidades especiais, é se é necessário submeter o projeto a um comitê de ética nos mesmos moldes de uma pesquisa médica. Esta tem sido uma questão apresentada em outros trabalhos como o de Musgrove-Chávez (2007) que ressaltou o atraso em projetos de sistemas computacionais submetidos ao IRB (Institucional Research Board) porque eles são submetidos, algumas vezes desnecessariamente, às mesmas regras das pesquisas médicas.

O que parece ser uma solução possível é a formação de comitês de ética por parte das organizações profissionais como UPA (Usability Professionals' Association), a ACM (Association for Computing and Machinery), o CREA (Conselho Regional e Engenharia e Arquitetura) entre outras e organizações acadêmicas como as Universidades, e uma vez que estudos como este envolvem seres humanos com entrevistas e observações e têm potencial de causar constrangimentos, mas não os expõe a riscos elevados, as etapas burocráticas possam ser reduzidas e a liberação 
da pesquisa seja mais rápida, incentivando outros pesquisadores a submeterem seus projetos para apreciação. Além de proteger os sujeitos da pesquisa, essa ação torna a pesquisa mais segura e aumenta a confiança e credibilidade dos seus resultados.

\subsection{Perspectiva de trabalhos futuros}

A avaliação situada de usabilidade pode ser aplicada em diversos ambientes e para outros equipamentos, a continuidade deste trabalho estaria na aplicação dos procedimentos em outros ambientes e estudar as particularidades de cada um deles, determinando o que é aplicável e o que não é, além de trazer novas propostas para o método.

O impacto da avaliação de usabilidade situada nas diversas fases do ciclo de vida de um projeto, também é um assunto que pode dar continuidade a este, fazendo a comparação dos resultados obtidos no início de um projeto, durante o desenvolvimento e ao final do projeto para verificar em qual etapa a avaliação é mais adequada.

O produto da avaliação situada de usabilidade são recomendações que servem de requisitos para uma nova iteração do ciclo de vida do projeto. O estudo do impacto dessas recomendações na equipe de projeto e no próprio projeto também pode ser feito.

Como mencionado anteriormente, uma questão levantada neste trabalho foi a necessidade de submeter um projeto de avaliação de usabilidade a um comitê de ética, essa questão poderia ser estudada mais profundamente e possivelmente estabelecer regras, distintas das regras para pesquisas médicas, mas, que tenham os mesmos objetivos, para projetos de engenharia que tenham potencial de causar constrangimentos aos envolvidos. 


\section{Referências}

ABNT - Associação Brasileira de Normas Técnicas. NBR ISO/IEC 12207 tecnologia de informação: processos de ciclo de vida de software. Rio de Janeiro: ABNT, 1998.

ABNT - Associação Brasileira de Normas Técnicas. NBR ISO 9241-11 Requisitos ergonômicos para trabalho de escritórios com computadores. Parte 11: Orientações sobre Usabilidade. Rio de Janeiro: ABNT, 2002.

ABNT - Associação Brasileira de Normas Técnicas. NBR 5413 Iluminância de interiores. Rio de Janeiro: ABNT, 1992.

ABRAHÃO, J. I.; PINHO, D. L. M. Teoria e prática ergonômica: seus limites e possibilidades. Escola, saúde e trabalho: estudo psicológicos; Brasília. Editora Universidade de Brasília, 1999.

ALLEN, M.; CURRIE, L.M.;BAKKEN, S.; PATEL, V.L.; CIMINO, J.J. Heuristic evaluation of paper-based Web pages: A simplified inspection usability methodology Journal of Biomedical Informatics 39 (2006) 412 - 423

Associação Brasileira de Ergonomia - ABERGO (2004). O que é Ergonomia. Disponível em : <http://www.abergo.org.br/oqueeergonomia.htm>.Acesso em: 22 jul. 2007

BASTIEN, C. \& SCAPIN , D. (1993). Ergonomic Criteria for the Evaluation of Human-Computer Interfaces.(Relatório de Pesquisa $N^{\circ}$. 156). INRIA -Institut National de Recherche en Informatique et en Automatique,Rocquencourt, França. 1993

BERNHAUPT, R. Home or Factory, Mobile or Multimodal: Challenges for Today's HCl Researchers. Canadá, Montreal: CHI'06 
BYRNE, M. D.; GREENE, K.K.; EVERETT, S.P.Usability of Voting System: Baseline Data for Paper, Punch Cards, and Lever Machines. EUA, San Jose. CHI 2007

CADERNOS DE ÉTICA EM PESQUISA. Brasília: Conep - Conselho Nacional de Ética em Pesquisa, n. 1, jul. 1998. Disponível em: <http://conselho.saude.gov.br/comissao/conep/publicacoes_cep.html>. Acesso em: 22 jul. 2007.

CASTILHO EA, KALIL J. Ética e pesquisa médica: princípios, diretrizes e regulamentações. Rev Soc Bras Med Trop. 2005;38:344-7.

CHUCHLAND, P. M. Matéria e Consciência: Uma introdução contemporânea à filosofia da mente. São Paulo: Ed. Unesp, 2004.

Dix, A. et al.; Human Computer Interaction, 2a. Ed. Prentice Hall Europe, 1998

EDWARDS, P. J.; JACKO, J. A.; MOLONEY, K. P.;SAINFORT, F. HCI Challenges Case Study: Implementing an Electronic Medical Record. Canadá, Montreal: $\mathrm{CHI} 06$

EMANUEL EJ, CROUCH RA, ARRAS JD, MORENO JD, GRADY C (eds) Ethical and regulatory aspects of clinical research. - The Nuremberg Code, p. 29. The Declaration of Helsinki, p. 30-32. The Johns Hopkins University Pres, p. 29, 2004.

GARMER, K.; YLVÉN, J.; KARLSSON, I.C.MA. User participation in requirements elicitation comparing focus group interviews and usability tests for eliciting usability requirements for medical equipment: a case study. International Journal of Industrial Ergonomics 33 (2004) 85 - 98

GLASCOCK, A. P.; KUTZIK, D. Realty Testing: $\mathbf{H C l}$ Challenges in NonTraditional Environments. Canadá, Montreal: CHI'06 
GOLDIM JR, FRANCISCONI CF. Os comitês de ética hospitalar. Revista de Medicina ATM 1995;15(1):327-334.

HALL, K. Testing in the hangar: user studies in a maintenance enviroment. Canadá, Montreal: CHI'06

HAN, S.; TÉTARD, F.; HARKKE, V.; COLLAN, M. Usability Evaluation of a Mobile Medical Information System for Military Physicians. Proceedings of the 40th Hawaii International Conference on System Sciences - 2007

HARTMANN, J., SUTCLIFFE, A., and DE ANGELI, A. 2007. Investigating attractiveness in web user interfaces. In Proceedings of the SIGCHI Conference on Human Factors in Computing Systems - EUA, San Jose:CHI '07

HAYNES, S.R.; PURAO, S. SKATTEBO, A.L. Situating Evaluation in Scenarios of Use. EUA, Chicago: CSW 2004.

HORSKY et al., Comprehensive Analysis of a Medication Dosing Error Related to CPOE. Journal of the American Medical Informatics Association, 2005; 12:377382

HYMAN, W. A. Errors in The Use of Medical Equipment. Human Error in Medicine. Lawrence Erlbaum Associates, Inc. LONDRES, 1994.

International Oraganization for Standardization. ISO 9241-11: ergonomic requirements for office work with visual display terminals (VDTs) - guidance on usability. Genebra, 1998.

International Oraganization for Standardization. ISO 9126-1: Software engineering Product quality - Part 1 : Quality model. Genebra, 2001.

International Oraganization for Standardization. ISO 9126-4: Software engineering Product quality - Part 4 : Quality in use metrics. Genebra, 2004. 
International Eletrotechnical Commission. IEC 60601-1: Medical electrical equipment - Part 1: General requirements for basic safety and essential performance. Genebra, 2005.

JAMBON, F. Reality Testing of Mobile Devices: How to ensure analysis validity? Canadá, Montreal: CHI'06

KJELDSKOV, J.; STAGE, J. New techniques for usability evaluation of mobile systems. Int. J. Human-Computer Studies 60 (2004) 599 - 620

KOPPEL, R.; METLAY, J. P.; COHEN, A.; ABALUCK, B.; LOCALIO, A. R.; KIMMEL, S. E.; STROM, B. L. Role of computerized physician order entry systems in facilitating medication errors. JAMA, 293 (10). 1197-1203

KUNIAVSKY, M. Observing the user experience: A practioner's guide to user research. EUA, São Francisco. Morgan Kauffmann, 2003

KUSHNIRUK, A.W., PATEL V.L. Cognitive and usability engineering methods for the evaluation of clinical information systems. Journal Biomedical Informatics 2004;37(1):56-76.

LEAPE, L. L. Error in medicine. JAMA, v. 272, n. 23, p.1851-7, 1994.

LILJEGREN, E., Usability in a medical technology context assessment of methods for usability evaluation of medical equipment. International Journal of Industrial Ergonomics 36 (2006) 345 -352

LILJEGREN, E.; OSVALDER, A. L., Cognitive engineering methods as usability evaluation tools for medical equipment. International Journal of Industrial Ergonomics 34 (2004) $49-62$ 
LILJEGREN, E.; OSVALDER,A. L.; DAHLMAN, S., Settings the requirements for a user-friendly infusion pump. Proceedings of the Human Factors and Ergonomics Society, 44th Annual Meeting, EUA, San Diego: 2000

LIU, Y.; OSVALDERA, A.-L.; DAHLMAN, S. Exploring user background settings in cognitive walkthrough evaluation of medical prototype interfaces: a case study. International Journal of Industrial Ergonomics 35 (2005) 379 - 390.

MINARDO, K. Hostile $\mathrm{HCl}$ : Research Methods for Unobservable Conflict Environments. Canadá, Montreal. CHI'06

MUSGROVE-CHÁVEZ, M.C. IRB: Taming the Wild? Rio de Janeiro, INTERACT 2007

NIELSEN, J., Enhancing the explanatory power of usability heuristics, CHI'94 Conference Proceedings, (1994).

REASON, J., Human Error. Cambridge University Press. 1990

ROCHA, H. V. ; BARANAUSKAS, M. C. - Design e Avaliação de Interfaces Humano-Computador Campinas, SP: NIED/UNICAMP, 2003

RUBIN, J. Handbook of Usability Testing. How to Plan, Design and Conduct Effective Tests. Wiley Technical Communication Library. 1994

ROZESTRATEN, R. J. A. Ergonomia no trânsito. Psicol. pesqui. transito, dez. 2005, vol.1, no.1, p.01-08.

SAlOVAARA, A.; OUlASVIRTA, A.; JACUCCI, G. "The Panopticon": A method for observing inter-group interactions. Canadá, Montreal: $\mathrm{CHI} 06$

SIEK, K. A.; CONNELLY, K. H. Lessons learned conducting user studies in a dialysis ward. Canadá, Montreal: CHI'06

SMITH BF. O tribunal de Nuremberg. Rio de Janeiro: F.Alves; 1970. 
TANG, C.; CARPENDALE, S. An Observational Study on Information Flow during Nurses' Shift Change. EUA, San Jose: CHI 2007

TULLIO, J.; DEY, A. K.; CHALECKI, J.; FOGARTY, J. How it works: A Field Study of Non-Technical Users Interacting with an Intelligent System. EUA, San Jose: CHI 2007

Universidade Federal de Santa Catarina (Org.). Checklist de aspectos ergonômicos. Disponível em: <- http://www.labiutil.inf.ufsc.br/ergolist/>. Acesso em: 31 maio 2007.

VIDAL, M. C.. Ergonomia na Empresa: útil, prática e aplicada. Rio de Janeiro: Editora Virtual Científica, 2002.

VIEIRA, S. Ética e metodologia na pesquisa médica. Rev. Bras. Saude Mater. Infant. 2005, vol. 5, no. 2 , pp. 241-245.

WEINGER, M.B., Anesthesia equipment and human error. Journal of Clinical Monitoring and Computing 15, $319-323$

WICKENS,C. D.; Engeneering, psychology and human performance. Upper Saddle River, NJ, EUA: Prentice Hall, 1999

WISNER, A. A inteligência no trabalho: textos selecionados de Ergonomia. (I. Ferreira \& R. Leal, Trads.) São Paulo: Fundacentro. 1994

WISNER, A. Por Dentro do Trabalho: Ergonomia: método e técnica. 2. ed. São Paulo: Ftd, 1987. 


\section{APÊNDICE I - Instrumento de observação}

\section{Hospital:}

Unidade:

Data:

Hora início:_término:

\section{Descrição do Ambiente}

Altura do equipamento (medir com uma fita métrica a distância entre o chão e o aparelho):

Espaço entre o leito e o equipamento (medir com uma fita métrica a distância entre o equipamento e o leito)

Há outros equipamentos por perto? (identificar os equipamentos, a localização e a distância do equipamento)

Luminosidade (medir com o luxímetro)

Descrever outros aspectos que forem observados

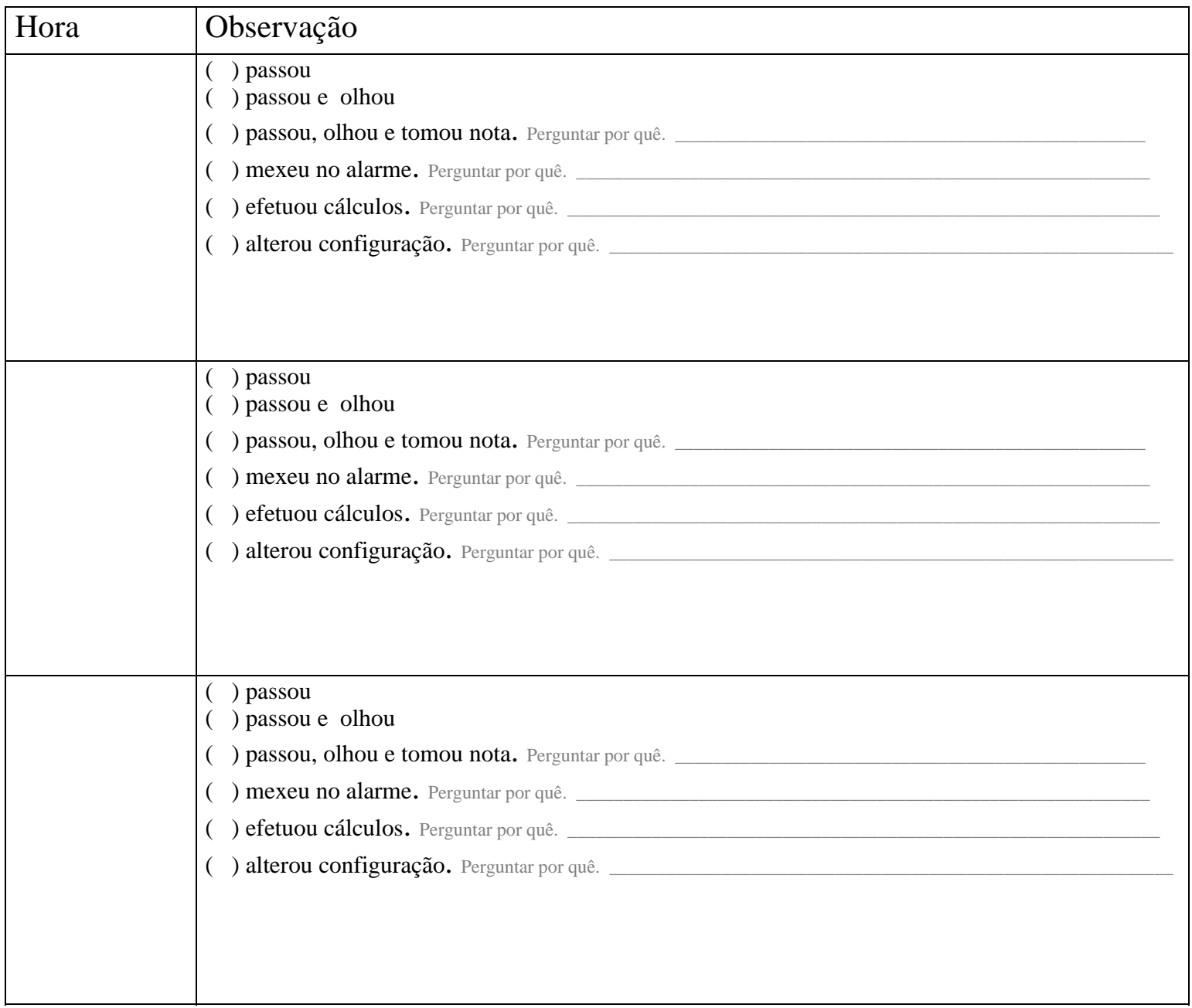




\section{APÊNDICE II - Instrumento de levantamento de perfil de usuário}

\section{Questionário de perfil}

Sexo : ( ) Feminino ( ) Masculino

Formação :

Idade :

Anos de Experiência:

Período de trabalho: ( ) manhã ( ) tarde ( ) noite

Trabalha em outro hospital?

( ) $\operatorname{sim}$ ( ) não. Em que período?

Conhece outros equipamentos da Dixtal?

( ) $\operatorname{sim}($ ) não

Tem familiaridade com eles?

( ) $\operatorname{sim}$ ( ) não

Já recebeu treinamento de algum equipamento?

( ) sim ( ) não. Quais?

Freqüência de uso dos computadores?

( ) todos os dias

( ) algumas vezes por semana

( ) menos de uma vez por semana

( ) não usa computadores

Faz uso de computadores para:

( ) trabalho/escola

( ) lazer

( ) outros

( ) não usa computadores 


\section{APÊNDICE III - Instrumento de entrevista}

Entrevista - número

Data:

Início:

Fim:

Questionário de aspectos subjetivos ( respondido após a realização da tarefa)

A tarefa foi concluída:

( ) mais do que satisfatoriamente

( ) satisfatoriamente

( ) insatisfatoriamente
Dificuldade na realização da tarefa

( ) muito fácil

( ) fácil

( ) difícil

( ) muito difícil

Dê notas de 0 a 5 para os seguintes itens :

tempo gasto na realização da tarefa:

satisfação ao realizar a tarefa:

tempo para aprender a realizar a tarefa:

Comentários:

Você já teve dificuldade ao usar o monitor?

Pode descrever uma situação?

Como você fez para resolver essa dificuldade? (sozinho, manual de operações, outro funcionário, ou ainda não conseguiu...)

Você já observou outras pessoas com a mesma dificuldade?

A que você atribui essa dificuldade? (treinamento, informações, experiência...)

Se você pudesse mudar alguma coisa no equipamento, o que você mudaria? 
APÊNDICE IV - Instrumento de observação de simulação da tarefa

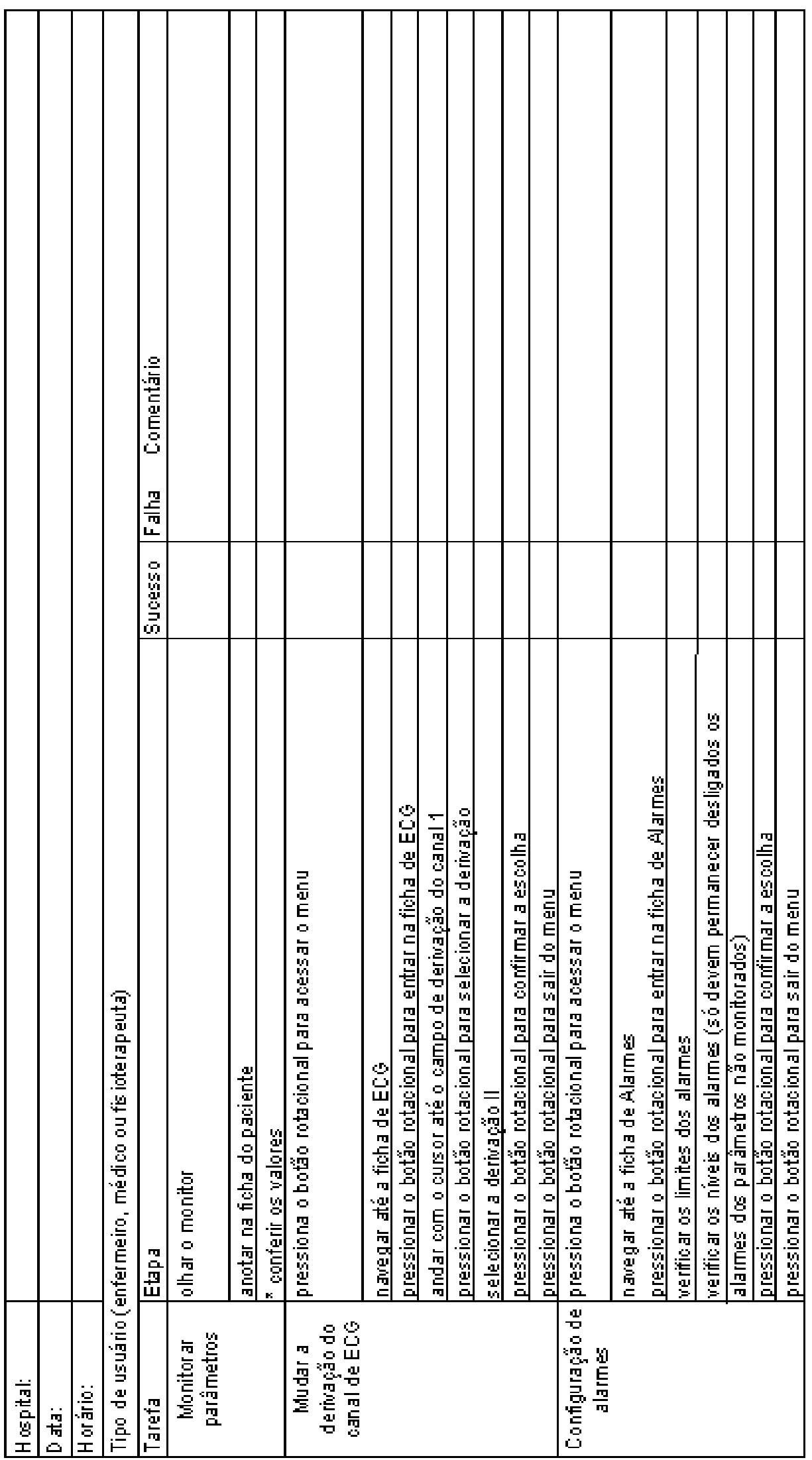




\section{APÊNDICE V - Documentos entregues ao CEP - HUIUSP}

São Paulo, 30 de novembro de 2007

\section{À Câmara de Pesquisa da Comissão de Ensino e Pesquisa e Ao Comitê de Ética em Pesquisa \\ Hospital Universitário da Universidade de São Paulo}

Senhor Coordenador,

O projeto de pesquisa Avaliação de usabilidade situada para aperfeiçoaamento de equipamentos médicos, cujo investigador principal é a Bárbara Dariano Silva, a ser realizado nas dependências do Hospital Universitário, foi analisado na Área da Divisão de Clínica Médica, sendo considerado exeqüível e de interesse pela área em questão. Como o investigador principal não pertence ao Hospital Universitário, o responsável pelo projeto na área será o Dr. Francisco Garcia Soriano.

Declaro que esta Diretoria e o responsável pelo projeto têm conhecimento dos procedimentos da Universidade de São Paulo no que se refere a excelência científica exigida, às características da revisão anônima por pares e aos termos da Resolução 196/96 do Conselho Nacional de Saúde.

Nestes termos, estaremos sempre à disposição da Câmara de Pesquisa e do Comitê de Ética em Pesquisa para dirimir qualquer dúvida que surja no decorrer da análise do presente projeto.

Atenciosamente,

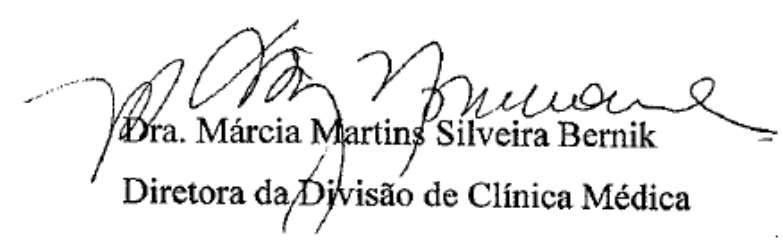


MINISTÉRIO DA SAÚDE

Conselho Nacional de Saúde

Comissâo Nacionel de Ética em Pesquisa - CONEP

FOLHA DE ROSTO PARA PESQUISA ENVOLVENDO SERES HUMANOS

Projeto de Pesquisa

Avallaçáo de usabilidade situada para aperfeicoamento de equipamentos médicos

Area de Conhecimento

3.00-Engenharias - 3.04 - Engenharia Elétric

Área(s) Temática(s) Especial(s)

Unitermos

usabilidade, equipamentos médicos, avaliaçăo situada

Sujeitos na Pesquisa

\begin{tabular}{|c|c|c|c|c|}
\hline $\begin{array}{l}N^{\circ} \text { de Sujeitos no Centro } \\
10\end{array}$ & $\begin{array}{c}\text { Total Brasil } \\
10\end{array}$ & $\begin{array}{l}N^{\circ} \text { de \$ujeitos Total } \\
10\end{array}$ & \multicolumn{2}{|c|}{$\begin{array}{l}\text { Grupos Especiais } \\
\text { Pessoas numa relação de dependência como presidiários, militares, } \\
\text { alunos, funcionários, etc. }\end{array}$} \\
\hline Placebo & $\begin{array}{l}\text { Medicamentos } \\
\text { HIV I AIDS } \\
\text { NĀO }\end{array}$ & $\begin{array}{r}\text { Wash-out } \\
\text { NÃO }\end{array}$ & $\begin{array}{c}\text { Sem Tratamento Especifico } \\
\text { NAOO }\end{array}$ & $\begin{array}{c}\text { Banco de Materiais Biológicos } \\
\mathrm{N} \not \mathrm{AO}\end{array}$ \\
\hline \multicolumn{5}{|c|}{ Pesquisador Responsável } \\
\hline \multicolumn{3}{|l|}{$\begin{array}{l}\text { Pesquisador Responsável } \\
\text { Lucia Vilela Leite Filgueiras }\end{array}$} & $\begin{array}{l}\text { CPF } \\
074.922 .728-12 \\
\end{array}$ & $\begin{array}{l}\text { Identidade } \\
8279856-4 \\
\end{array}$ \\
\hline \multicolumn{3}{|c|}{$\begin{array}{l}\text { Ärea de Especializaçăo } \\
\text { INTERAÇAO HOMEM-COMPUTADOR }\end{array}$} & $\begin{array}{l}\text { Maior Titulaçăo } \\
\text { DOUTORA }\end{array}$ & $\begin{array}{l}\text { Nacionalidade } \\
\text { BRASILEIRA }\end{array}$ \\
\hline \multicolumn{3}{|c|}{$\begin{array}{l}\text { Endereço } \\
\text { AV PROF LUCIANO GUALBERTO TRAV } 3 \text { NO } 158\end{array}$} & $\begin{array}{l}\text { Bairro } \\
\text { CIDADE UNIVERSITARIA }\end{array}$ & $\begin{array}{l}\text { Cidade } \\
\text { SÃO PAULO - SP } \\
\end{array}$ \\
\hline $\begin{array}{l}\text { Código Postal } \\
\text { 05508-900 }\end{array}$ & \multicolumn{2}{|c|}{$\begin{array}{l}\text { Telefone } \\
11.3091 .5200 / 11.3064 .7974\end{array}$} & $\begin{array}{l}\text { Fax } \\
11.3091 .5294\end{array}$ & $\begin{array}{l}\text { Email } \\
\text { lucia.filgueiras@poli.usp.br }\end{array}$ \\
\hline
\end{tabular}

Termo de Compromisso

Declaro que conheço e cumpritei os requisitos da Res. CNS 196/96 e suas complementares. Comprometo-mea utilizar os materiais e dados

coletados exclusivamente para os fins previstos no protocolo e publicar os resultados sejam ojes favoraveis ou dag

Aceito as responsabilidades pela conduçáo cientifica do projeto acima

Data: $03,12,2001$

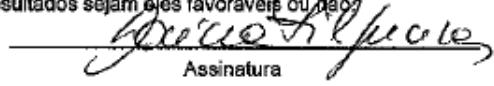

\begin{tabular}{|c|c|c|c|}
\hline \multicolumn{2}{|c|}{$\begin{array}{l}\text { Nome } \\
\text { Hospital Universitário - Universidade de Săo Paulo }\end{array}$} & $\begin{array}{l}\text { CNPJ } \\
63.025 .530 / 0085-12\end{array}$ & $\begin{array}{c}\text { Nacional/internacional } \\
\text { Nacional }\end{array}$ \\
\hline \multicolumn{2}{|c|}{$\begin{array}{l}\text { Unidade/Orgão } \\
\text { Hospital Universitário da Universidade de Săo Pauło }\end{array}$} & $\begin{array}{c}\text { Participaç̆̃o Estrangeira } \\
\text { NÄO }\end{array}$ & $\begin{array}{c}\text { Projeto Multicêntrico } \\
\text { NÅ̊O }\end{array}$ \\
\hline \multicolumn{2}{|l|}{$\begin{array}{l}\text { Endereç } \\
\text { Av. Professor Lineu Prestes, } 2565\end{array}$} & $\begin{array}{l}\text { Bairro } \\
\text { Butantă }\end{array}$ & $\begin{array}{l}\text { Cidade } \\
\text { Săo Paulo.SP }\end{array}$ \\
\hline $\begin{array}{l}\text { Código Postal } \\
05508900\end{array}$ & $\begin{array}{l}\text { Telelone } \\
\text { (11) } 3812-7711\end{array}$ & $\begin{array}{l}\text { Fax } \\
\text { (11) } 3812-8004\end{array}$ & $\begin{array}{l}\text { Email } \\
\text { cep@hu.usp.br }\end{array}$ \\
\hline
\end{tabular}

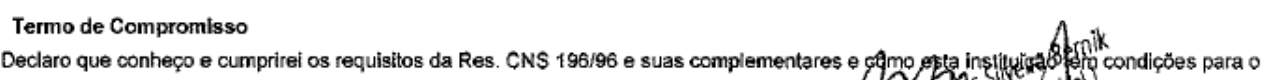

desenvolvimento deste projeto, autorizo sua execuçăo.

Nata: It, 00,2008

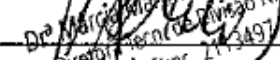

\begin{tabular}{|c|c|c|c|}
\hline \multicolumn{4}{|c|}{ Vinculada } \\
\hline \multicolumn{2}{|c|}{$\begin{array}{l}\text { Nome } \\
\text { Escolla Politécnica da Universidade de Sâo Paulo }\end{array}$} & $\begin{array}{ll}\text { CNPJ } \\
. .\end{array}$ & $\begin{array}{c}\text { Nacional//nternacional } \\
\text { Nacional }\end{array}$ \\
\hline \multicolumn{2}{|c|}{$\begin{array}{l}\text { Unidade/Órgáo } \\
\text { Departamento de Engenharia de Computaçăo e Sistemas Digitais }\end{array}$} & $\begin{array}{c}\text { Participaçăo Estrangeira } \\
\text { NÃO }\end{array}$ & $\begin{array}{l}\text { Projeto Multicentrico } \\
\text { NÃO }\end{array}$ \\
\hline \multicolumn{2}{|c|}{$\begin{array}{l}\text { Endereşo } \\
\text { Av. Prof. Luciano Gualberto, travessa } 3 n^{\circ} 380\end{array}$} & $\begin{array}{l}\text { Bairro } \\
\text { Cidade Universitária }\end{array}$ & $\begin{array}{l}\text { Cidade } \\
\text { Sáo Paulo - }\end{array}$ \\
\hline $\begin{array}{l}\text { Código Postal } \\
05508-900\end{array}$ & $\begin{array}{l}\text { Telefone } \\
\text { (11) } 3091-5363\end{array}$ & Fax & Email \\
\hline
\end{tabular}

Termo de Compromisso

Declaro que conhego e cumprirei os requisitos da Res. CNS 196/96 e suas complementares.

Data: $03,12,2007$

Chefe do departamento de eng. de computacias sistemas digrtais

O Projeto deverá ser entregue no CEP em até 30 dias a partir de 02/12/2007. Näo ocorrendo a entrega nesse prazo esta Folha de Rosto será INVALIDADA. 


\section{DETALHAMENTO FINANCEIRO}

\section{Fonte de Recursos}

[ ] Agência de Fomento (Fundação): Qual? (Anexar relatório do Fomento)

[ ] Iniciativa Privada (Laboratórios, etc.): Qual?

$[\mathrm{x}]$ Năo se aplica

VALOR DOS RECURSOS RS

II. Recursos a serem despendidos com o Projeto de Pesquisa:

\begin{tabular}{l|l}
\hline Recursos Humanos & \\
(a) Contratação de Serviços Eventuais: & R\$ \\
Principal & R\$ \\
Encargos (IR, ISS, etc.) & RS \\
(b) Seguro de Vida e Saúde do Pessoal envolvido: &
\end{tabular}

Materiais

(a) Aquisiçăo de material de consumo para a pesquisa

(b) Aqquisiçăo de equipamentos:

[ ] Importaçăo

[ ] Mercado Interno

\begin{tabular}{|l|l|}
\hline CUSTO & R\$ \\
\hline $\begin{array}{l}\text { Outros } \\
\text { (a) Fundo de Pesquisa HU/USP } \\
\text { (b) outros gastos (especificar): }\end{array}$ & \\
\hline TOTAL DE RECURSOS DESPENDIDOS & R\$ \\
\hline Data: _._. & \\
\hline
\end{tabular}




\section{CADASTRO DE PROTOCOLO DE PESQUISA}

REGISTRO (uso reservado à Comissão de Ensino e Pesquisa)

$\mathrm{N}^{\circ}$ de Registro HU:

Data de Entrada :

SISNEP CAAE:

1. Título do Projeto de Pesquisa (não abreviar):

Avaliação situada de usabilidade para aperfeiçoamento de equipamentos médicos

\section{Palavras chaves que caracterizam o assunto da Pesquisa:}

Usabilidade - equipamentos médicos - avaliação situada

3. Resumo do Projeto de Pesquisa (Além deste resumo, deverá ser anexada cópia do Projeto de Pesquisa completo, apresentado de maneira clara que deve compreender: resumo, introdução e justificativa, com sintese bibliografica; plano de trabaiho; material e métodos e forma de análise dos resultados):

Para reduzir custos e processos ineficientes e aumentar a qualidade do cuidado com os pacientes a área da saúde tem feito cada vez mais uso da tecnologia da informação e a cada dia, o usuário de sistemas médicos se depara com mais equipamentos médicos dotados de interfaces computacionais mais complexas. Porém, ao mesmo tempo que se faz mais uso da computação e da tecnologia da informação os erros associados à interação homem máquina têm crescido proporcionalmente.

Para que esses equipamentos possam desempenhar sua função adequadamente, além de suas funcionalidades e aspectos de segurança, como contaminações e interferências eletromagnéticas, um outro aspecto precisa ser considerado ao projetar, produzir, comprar e utilizar esses aparelhos: a interação dos usuários com eles. Uma avaliação adequada da usabilidade, levando em consideração as necessidades dos usuários e o contexto em que os equipamentos estão inseridos podem proporcionar projetos de equipamentos médicos que além de atender as demandas das atividades dos profissionais da saúde, minimizam a probabilidade de erros relacionados à interação com o sistema.

Sabe-se que as avaliações situadas, ou seja, avaliações realizadas no ambiente de uso do equipamento, com situações e usuários mais próximos das condições reais de utilização, produzem um resultado diferente da avaliação em laboratório, pois é possível identificar com mais clareza as dificuldades e necessidades dos usuários, possibilitando alterações de projeto mais efetivas. Pode-se obter informações a respeito do conforto ou desconforto do usuário no uso do equipamento e levantar suas necessidades mais relevantes para realizar suas tarefas de forma mais rápida e adequada.

O objetivo desta pesquisa é obter essas informações sobre um equipamento e validar a proposta de avaliação.

4. Pesquisador Responsável:

Prof.a Dr.a Lúcia Vilela Leite Filgueiras

\begin{tabular}{|l|l|l|}
\hline 5. Equipe de Trabalho (Co-Autores): & E-mail: & Instituição: \\
\hline Bárbara Dariano Silva & barbara.silva@poli.usp.br & EPUSP \\
Elder Viera da Costa & evcosta@dixtal.com.br & Dixtal Biomédica \\
Dr. Francisco Garcia Soriano & gsoriano@usp.br & HU-USP \\
& & \\
\hline 6. Finalidade da Pesquisa: & & \\
\hline
\end{tabular}




[ ] Iniciação Científica [ x ] Mestrado [ ] Doutorado [ ] Pesquisa cientifica regular
[ ] Aplicação tecnológica

7. Instituições envolvidas (especificar):

[ x ] HU - Área: UTI adulto

[ ] Outras Instituições:

\section{Pesquisa:}

[ ] Seres Humanos

[ $\mathrm{x}$ ] Outros (amostra de material, dieta, especificar): monitor de sinais vitais - DX2020

\section{Materiais:}

[ ] Laboratorial

[ ] Peças anatômicas e cadáveres

[ ] Prontuários de pacientes

$[\mathrm{x}$ ] Entrevistas e questionários

[ ] Tecidos, órgãos, flufdos orgânicos

[ ] Outros (especificar):

[ ] Técnicas operatórias

10. A pesquisa envolve (preencher mais de um se necessário):

[ ] Isótopo radioativo, dispositivo gerador de radiação ionizantes

[ ] Microorganismo patogênico

[ ] Ácidos nucleares recombinantes

[ ] Outros (especificar):

11. Existe algum risco ambiental e/ou biológico com o descarte dos subprodutos e/ou reagentes de sua pesquisa?
[ ] SIM
[ $x$ ] NÃO

12. Delineamento da pesquisa:

[ ] Avaliação de servico

[ ] Estudo observacional (transversal, caso-controle, coorte)

[ ] Ensaio Clínico

[ ] Estudo antropológico

[ $\mathrm{x}$ ] Outros (especificar): avaliação de usabilidade

13. Pesquisa em áreas temáticas especiais:

[ ] Genética humana

[ ] Reprodução humana

[ ] Novos Fármacos, Vacinas e Testes Diagnósticos

[ ] Equipamentos, insumos e dispositivos para a saúde novos, ou nầo registrados no país

[ ] Novos procedimentos ainda não consagrados na literatura

[ ] Populações indígenas

[ ] Projetos que envolvam aspectos de biossegurança 
[ ] Pesquisas coordenadas do exterior ou com participação estrangeira e pesquisas que envolvam remessa de material biológico para o exterior

14. Patrocínio (descrever e preencher impresso "Detalhamento Financeiro - ANEXO V")

Não há.

15. Utilizará a infra-estrutura e recursos humanos do Hospital Universitário para o desenvolvimento da pesquisa? (especificar):

Entrevistas com os funcionários da UTI adulto.

16. Necessitará de exames complementares e/ou outros procedimentos fora da rotina, bem como, de permanência hospitalar? (especificar):

O estudo requer permanência na UTI adulto por períodos de 3 horas.

17. Cronograma de execução da pesquisa:

Início: 1 1

Término:

1 I

Data:

1 
18. Parecer da Câmara de Pesquisa - CPesq:

Presidente:

Data:

Assinatura

19. Parecer do Comitê de Ética em Pesquisa - CEP:

Coordenador:

Data: 
20. Termo de Compromisso do Pesquisador com o Hospital Universitário:

Comprometo-me a respeitar as Normas da Instituição, bem como:

1. Aguardar a emissâo do documento de aprovação do projeto de pesquisa pelo Comitê de Ética em Pesquisa do HU/USP, para iniciar a coleta de dados, conforme estabelece a Resolução 196/96, do Conselho Nacional de Saúde, do Ministério da Saúde (item IX.2);

2. Apresentar, por escrito, relatório anual do andamento da presente pesquisa (no caso de áreas temáticas os relatórios deverão ser semestrais);

3. Comunicar, por escrito, qualquer alteração do cronograma pré-estabelecido para o desenvolvimento da presente pesquisa;

4. Comunicar, por escrito, qualquer mudança na metodologia previamente estabelecida, e devidamente aprovada pela Câmara de Pesquisa do HU/USP e áreas envolvidas;

5. Apresentar relatório final consubstanciado dos resultados e conclusôes;

6. Quando resultados globais ou parciais da presente pesquisa forem divulgados ou publicados, sempre deverá constar que os mesmos foram desenvolvidos no Hospital Universitário da USP.

Ciente e de acordo:

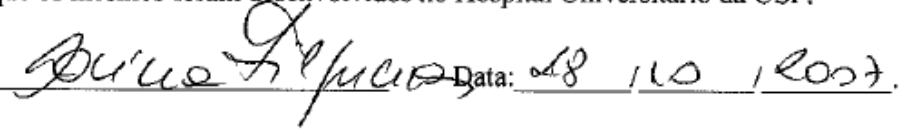

21. Na presente data tomo ciência da APROVAÇÃO do projeto de pesquisa por mim solicitada. Nome:

Assinatura:

Data 1

\section{Apresentação do Relatório Final}

Data da entrega:

Parecer:

Coordenador:

Data:

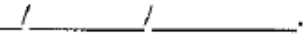


TERMO DE CONSENTIMENTO LIVRE E ESCLARECIDO

NOME:

Documento de identidade:

SEXO: [ ] masculino [ ] feminino

DATA DE NASCIMENTO:

DATA:

HORA:

Você está sendo convidado a participar de uma pesquisa acadêmica (Avaliação de Usabilidade Situada para Aperfeiçoamento de Equipamentos Médicos) que tem como objetivo propor uma forma de avaliar a eficiência de equipamentos médicos.

Avaliar o equipamento pode trazer benefícios tanto para quem produz os equipamentos como para quem os usa. Para quem produz é uma maneira de fazer um produto que agrade mais o seu cliente; e para quem usa, o equipamento estará mais de acordo com as suas necessidades.

A pesquisa consiste em observação do manuseio do equipamento, questionários e entrevistas. As entrevistas serão gravadas e só serão ouvidas pelos pesquisadores envolvidos neste trabalho.

Todas as informações pessoais resultantes desta pesquisa serão tratadas de forma confidencial e não serão reveladas ou divulgadas.

A qualquer momento da pesquisa o seu consentimento pode ser retirado e não concordar em participar da pesquisa não trará nenhuma conseqüência.

[ ] SIM, concordo em participar da pesquisa

[ ] NÃO concordo em participar da pesquisa

Declaro que, após convenientemente esclarecido pelo pesquisador e ter entendido o que me foi explicado, consinto em participar do presente Projeto de Pesquisa

São Paulo, de de 20

Para esclarecimento de dúvidas:

PCS - Departamento de Engenharia de Computação e Sistemas Digitais Bárbara Dariano Silva : barbara.silva@poli.usp.br

Av. Prof. Luciano Gualberto, travessa $3 n^{\circ} 158$

Cidade Universitária - São Paulo - SP

05508-900

telefone:3091-5200

CEP-HU

Av. Prof. Lineu Prestes, 2565

Cidade Universitária - São Paulo - SP

05508-900

Telefones: 3039- 9457 ou 3039-9479

e-mail: cep@hu.usp.br 
São Paulo, $1^{\circ}$ de fevereiro de 2008.

$I l^{m o(a)} \cdot S^{p(a)}$.

Dra. Lucia Vilela Leite Filgueiras

Departamento de Engenharia de Computação e Sistemas Digitais

Escola Politécnica

UNIVERSIDADE DE SÃO PAULO

REFERENTE: Projeto de Pesquisa "Avaliação de usabilidade situada para aperfeiçoamento de equipamentos médicos" - Co-autor(es): Bárbara Dariano Silva; Elder Vieira da Costa; Prof. Dr. Francisco Garcia Soriano-CEP-HU/USP: 786/07 SISNEP CAAE: 0068.0.198.198-07.

Prezado(a) Senhor(a)

O Comitê de Ética em Pesquisa do Hospital Universitário da Universidade de São Paulo, em reunião ordinária realizada no dia $1^{\circ}$ de fevereiro de 2008 , analisou o projeto de pesquisa acima citado, considerando-o como APROVADO, bem como seu Termo de Consentimento Livre e Esclarecido.

Lembramos que cabe ao pesquisador elaborar e apresentar a este Comitê, relatórios anuais (parciais ou final, em função da duração da pesquisa), de acordo com a Resolução 196/96 do Conselho Nacional de Saúde, item IX.2 letra c.

O primeiro relatório está previsto para $1^{\circ}$ de fevereiro de 2009.

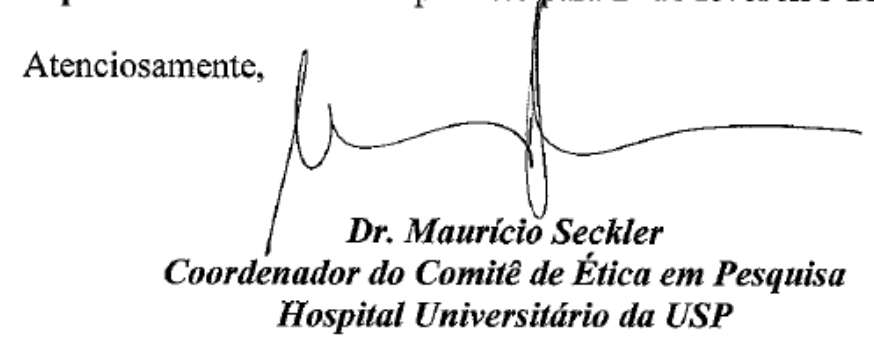

